\title{
Recent Advances in the Synthesis of Sulfides, Sulfoxides and Sulfones via C-S Bond Construction from Non-Halide Substrates
}

\author{
Rui Zhang ${ }^{\dagger}$, Huaiwei Ding ${ }^{\dagger}$, Xiangling Pu, Zhiping Qian and Yan Xiao * \\ School of Pharmaceutical Engineering, Shenyang Pharmaceutical University, 103\# Wenhua Road, \\ Shenyang 110016, China; rzm6767@163.com (R.Z.); dinghuaiwei627@163.com (H.D.); \\ a1521419442@163.com (X.P.); QZP13076029390@163.com (Z.Q.) \\ * Correspondence: xiaoyan@syphu.edu.cn \\ † These authors contributed equally to this work.
}

Received: 14 October 2020; Accepted: 16 November 2020; Published: 17 November 2020

\begin{abstract}
The construction of a C-S bond is a powerful strategy for the synthesis of sulfur containing compounds including sulfides, sulfoxides, and sulfones. Recent methodological developments have revealed lots of novel protocols for C-S bond formation, providing easy access to sulfur containing compounds. Unlike traditional Ullmann typed C-S coupling reaction, the recently developed reactions frequently use non-halide compounds, such as diazo compounds and simple arenes/alkanes instead of aryl halides as substrates. On the other hand, novel C-S coupling reaction pathways involving thiyl radicals have emerged as an important strategy to construct C-S bonds. In this review, we focus on the recent advances on the synthesis of sulfides, sulfoxides, and sulfones from non-halide substrates involving C-S bond construction.
\end{abstract}

Keywords: sulfide; sulfoxide; sulfone; C-S bond construction

\section{Introduction}

Sulfur containing compounds are a fundamental building block in organic synthesis [1,2]. They are also of great significance in bioactive natural products, pharmaceutical drugs, pesticides, and materials [3-8]. As shown in Figure 1, sulfur containing compounds, such as sulfides, sulfoxides, and sulfones, constitute a large portion of pharmaceutical drugs possessing a variety of biological activities. Given the great importance of sulfur containing compounds, intensive efforts have been made to develop effective synthetic methods. The construction of C-S bond is considered as an efficient strategy for the synthesis of sulfur containing compounds. The traditional Ullmann typed reaction, which has been well established in the past several decades, has provided lots of synthetic protocols for diaryl sulfides and aryl alkyl sulfides through transition-metal catalyzed C-S coupling reaction of aryl halides with aryl thiols or other sulfur precursors [9-11]. Methodological advancements in $\mathrm{C}-\mathrm{H}$ functionalization have led to the development of a variety of useful transformations to prepare sulfur containing compounds directly from (hetero)arenes and alkanes [12,13]. In very recent years, many novel strategies involving thiyl radicals have emerged as powerful tools for constructing C-S bonds in very facile manner using non-halide substrates.

In this review, we highlight the very recent advances in novel strategies that take advantage of C-S bond construction for the synthesis of sulfides, sulfoxides, and sulfones from non-halide substrates. 


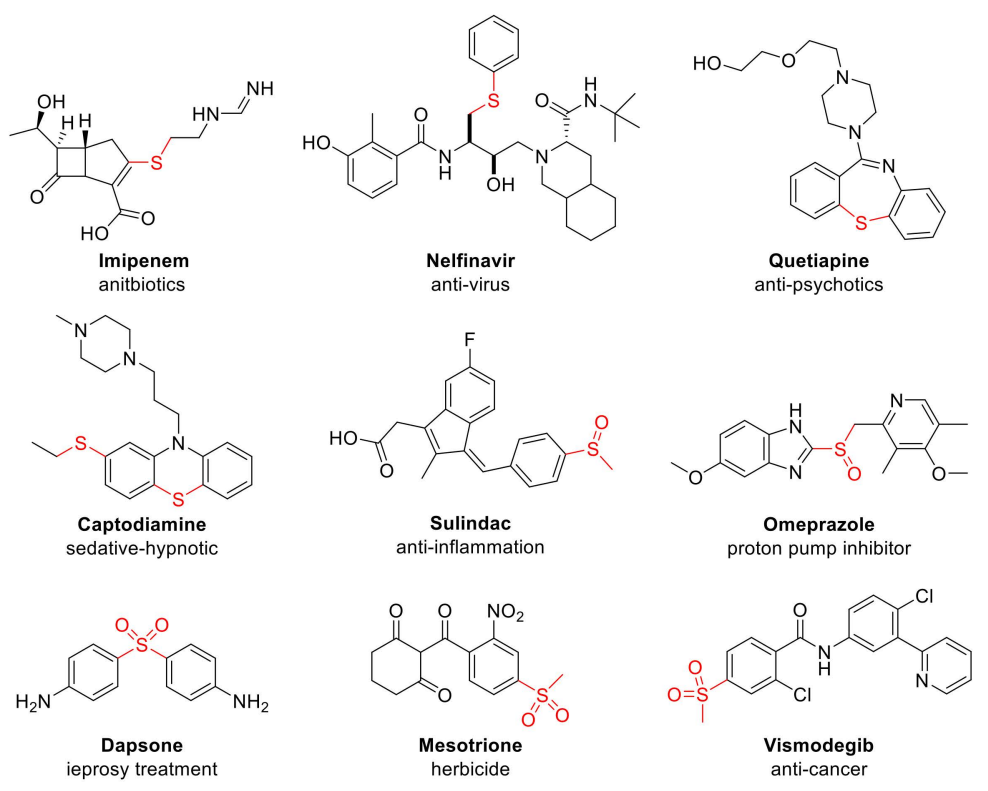

Figure 1. Representative drugs featured by sulfide, sulfoxide, or sulfone.

\section{Synthesis of Sulfides via C-S Bond Construction}

Traditional preparation of diaryl sulfides or aryl alkyl sulfides relies on the coupling reaction of aryl halides with thiols, disulfides, elemental sulfur, or other sulfur containing reagents. These conversions often require the employment of transition-metal catalysts and ligand in the presence of base. Recent research demonstrates that non-halide substrates, such as diazo compounds and simple arenes/alkanes, successfully coupled with thiol or disulfides to afford the corresponding sulfides. On the other hand, the sulfur containing reagents such as thiol and elemental sulfur, which are often used in the Ullmann typed C-S coupling reactions, also found wide application in the synthesis of sulfides from non-halide substrates. In this part, the synthetic methods for sulfides will be classified and discussed by different sulfenylation sources.

\subsection{Disulfide as Sulfenylation Source}

The S-S bond of disulfide can be reversibly cleaved when exposed to heating, photoirradiation, or transition-metal catalyst such as rhodium catalyst [14]. The generated active organothio intermediates such as thiyl radicals and sulfoniums, can easily couple with partners to afford sulfides. In addition, disulfide is a favorable sulfenylation source as it is stable and odorless.

\subsection{1. $\mathrm{C}\left(\mathrm{sp}^{3}\right)$-S Bond Formation with Disulfide}

Diazo compounds are widely used in organic synthesis for constructing new bonds. Generally, photoinitiated, thermal, or transition metal catalyzed decomposition of the diazo compound affords the corresponding carbene or metal carbenoid, which subsequently undergo various transformations $[15,16]$.

In 2016, the Lee group reported a rhodium pivalate-catalyzed direct sulfenylation of diazooxindoles using disulfide as the sulfenylation reagent via intermolecular C-S bond formation to synthesize thioindoles (Scheme 1) [17]. In this conversion, the diazo compound was converted to rhodium carbenoid, which further reacted with disulfide to afford a C-S bond. The subsequent S-S cleavage led to the formation of sulfides and cyclohexenylsulfide, respectively. In the developed reaction system, diazooxindoles reacted with a variety of alkyl or aryl disulfides to afford sulfide or dithioacetals under very mild condition. Generally, the reaction of diazo compounds with alkyl disulfides predominantly gave monoalkylthioindoles. However, when the 5- position of diazooxindoles was substituted with chloro, the reactions gave dialkylthiooxindoles as products. The same results were observed with the reaction of diaryldisulfides, which afforded diarylthiooxindoles in the conversion. It is interesting that 
the reaction of diazo compounds with dicycloalkyl disulfide provided both 3-cycloalkylthiooxindoles and 3-cycloalkenylthiooxindoles.

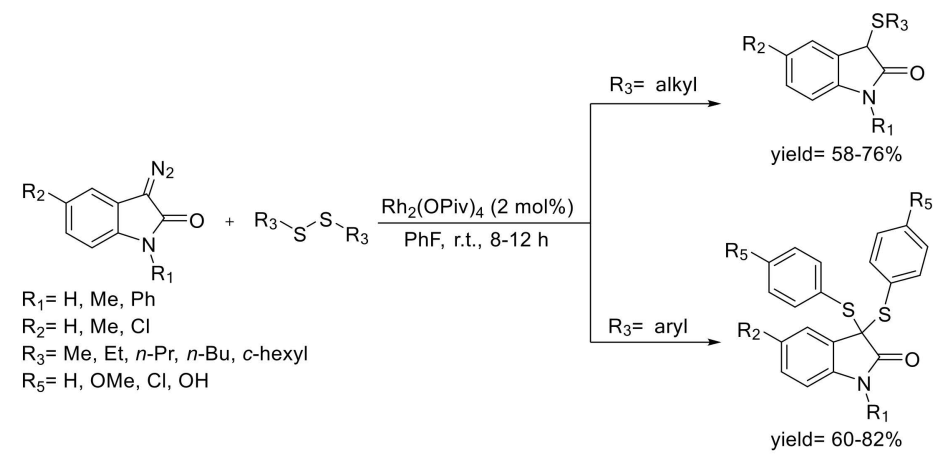

Scheme 1. C-S coupling reaction of diazo compounds and disulfides.

$\mathrm{N}$-tosylhydrazone is a readily available alkenyl source through the generation of metal-carbene species. In 2018, the Zhang and Wang group developed a $\mathrm{Cu}(\mathrm{I})$ catalyzed protocol for the synthesis of dithioacetals via C-S coupling reaction of $N$-tosylhydrazones and disulfides (Scheme 2) [18]. $\mathrm{N}$-tosylhydrazone functioned as a precursor of diazo compound in this reaction. The reaction occurred at $60{ }^{\circ} \mathrm{C}$ in the presence of $\mathrm{CuI}, 1,10$-phenanthroline (1,10-phen) and $t$-BuONa in DMF. This protocol was featured by a broad substrate scope. A great variety of $\mathrm{N}$-tosylhydrazones and disulfides were successfully converted into the corresponding dithioacetals in moderate to good yields.

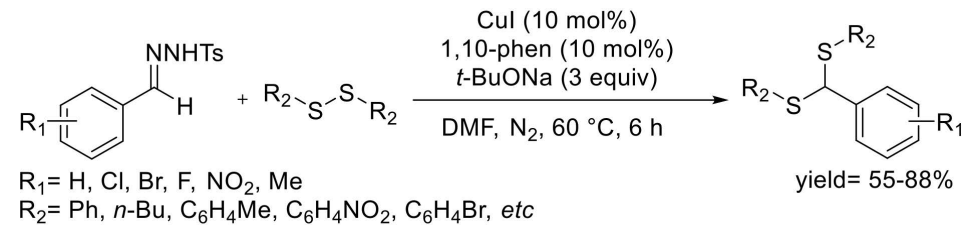

Scheme 2. Copper catalyzed synthesis of dithioacetals from tosylhydrazones.

$\mathrm{C}-\mathrm{C}$ bond fragmentation is a useful method to provide a fragment for the functionalization of molecules and has been extensively applied in organic synthesis [19]. In recent years, C-C bond cleavage/sulfenylation reactions via radical pathways have emerged as a practical tool for the synthesis of aryl alkyl sulfides [20].

In 2018, the $\mathrm{Wu}$ group reported a facile method for the synthesis of aryl methyl sulfides by treating di-tert-butyl peroxide (DTBP) with diaryl disulfide in acetonitrile (Scheme 3) [21]. In this conversion, di-tert-butyl peroxide gave methyl radicals under heating condition and the methyl radicals subsequently reacted with diaryl disulfide to afford aryl methyl sulfides.

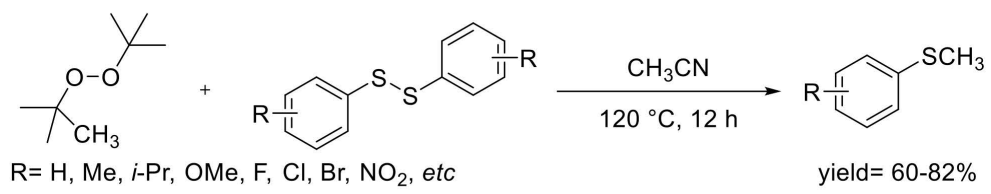

Scheme 3. Synthesis of aryl methyl sulfides using diaryl sulfides and DTBP.

In 2019, the Kwon group developed a dealkenylative thiolation method for the synthesis of aryl alkyl sulfides (Scheme 4) [22]. The isopropenyl group of substrate was easily removed via 
C-C bond cleavage by the ozonolysis of alkenes at $-78{ }^{\circ} \mathrm{C}$ and the followed $\mathrm{Fe}(\mathrm{II})$ salt mediated single electron transfer (SET)-based reductive cleavage resulted in the formation of alkyl radicals, which can be trapped with an aryl disulfide to form a $C\left(s p^{3}\right)-S$ bond. This method was featured by mild condition and high efficiency. The formation of C-S bond was accomplished within only $1 \mathrm{~min}$. Moreover, this method is practical as it can be applied in the dealkenylative thiolation of (exo-methylene) cycloalkanes and methylcycloalkenes. Alkanes containing exo-methylene group were converted into the corresponding phenylthiyl-containing methyl carboxylates and methylcycloalkenes were converted into phenylthio-aldehydes.

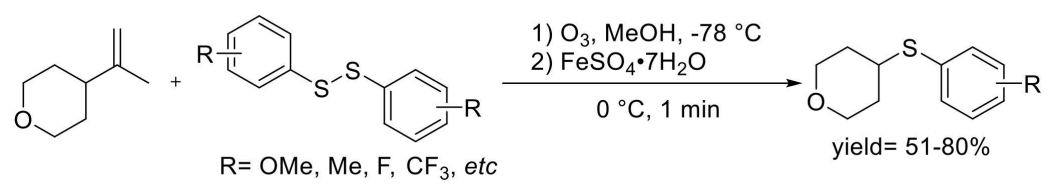

Scheme 4. Dealkenylative thiolation with diaryl sulfides.

In 2019, the Abbasi group reported a decarbonylative thiolation of 2-phenylpropanal with disulfides in the presence of morpholine and $\mathrm{K}_{2} \mathrm{CO}_{3}$ in DMF at $130^{\circ} \mathrm{C}$ (Scheme 5) [23]. This conversion provided the aryl benzyl sulfides in good to excellent yields. This reaction can be scaled up to $1 \mathrm{~g}$ with good yield. Moreover, a one-pot synthesis of aryl benzyl sulfides from simple aryl halides, $\mathrm{CS}_{2}$ and $\mathrm{KCN}$ was also developed in their work.

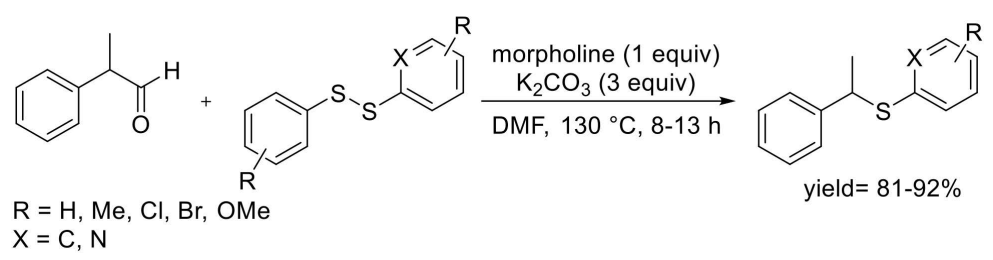

Scheme 5. Decarbonylative thiolation of aldehydes with disufides.

$\mathrm{C}-\mathrm{H}$ sulfenylation represents an atom-economic strategy for the synthesis of sulfides as it is employs simple arenes or alkanes as substrates. In 2019, the Yang group reported an unprecedented site-selective $\mathrm{C}\left(s p^{3}\right)$-H sulfenylation of alkyl tosylamides at the $\delta$-position (Scheme 6) [24]. The C-S coupling reaction occurred to $\mathrm{N}$-fluoro-tosylamide and diaryl disulfide at $40{ }^{\circ} \mathrm{C}$ in the presence of $\mathrm{Cu}$ (acac) $)_{2}, 1,10$-phen, $\mathrm{Na}_{2} \mathrm{HPO}_{4}$ and indium powder under the irradiation of blue LED light. This protocol was compatible with various diaryl disulfides, and even dibenzyl disulfides and diphenyl diselenides. It is noteworthy that $\mathrm{C}-\mathrm{H}$ thiolation using this protocol exhibited high site-selectivity and substrate compatibility with $\mathrm{N}$-fluoro-tosylamides, no matter the $\delta$-C located at a chain or a cycle. It was suitable for the thiolation of $1^{\circ}, 2^{\circ}$, and $3^{\circ} \mathrm{C}-\mathrm{H}$ bonds, and the reactivity of hydrogen atoms decreased in the order tertiary $>$ secondary $>$ primary. On the other hand, the reactivity of aryl disulfide was higher than that of aliphatic disulfide, and electro-donating group was more favorable than electro-withdrawing group on the phenyl ring of diaryl disulfide. Examples of applying this protocol in the synthesis of complex biological active compounds were also reported in their work. 

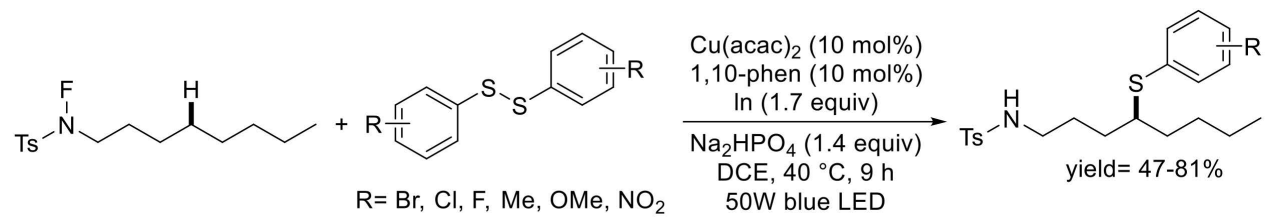

Scheme 6. Sulfenylation of tosylamides with disulfides.

In the same year, the Meng group reported a $\mathrm{Cu}(\mathrm{I})$-catalyzed sulfenylation of 1,3-dicarbonyl substrates with diaryl sulfides (Scheme 7) [25]. This protocol was featured by a mild condition, simple procedure, and satisfying yield. This coupling reaction occurred in the presence of $\mathrm{CuI}$ in acetonitrile at room temperature in the darkness, providing the corresponding sulfides in moderate to excellent yields. Moreover, this protocol was also compatible with the $\beta$-carbonyl amide and dialkyl sulfide.

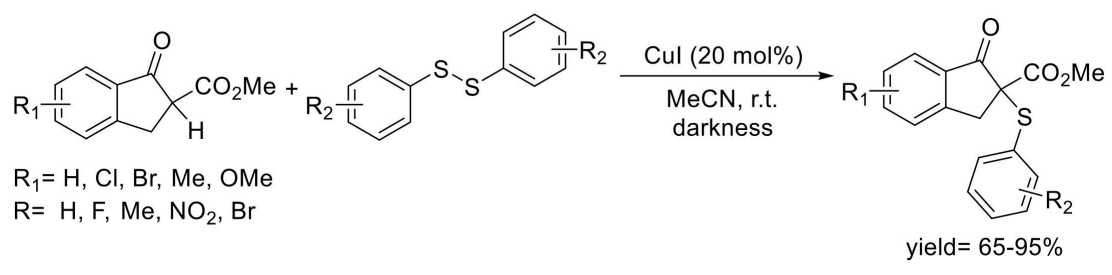

Scheme 7. Sulfenylation of 1,3-dicarbonyl substrates with disulfides.

Chalcogenium ions can be readily captured by nucleophile-tethered alkenes to afford functionalized chalcogenides. In 2018, the Zhao group developed an efficient and practical protocol for the synthesis of sulfides from nucleophile tethered alkenes and diaryl disulfides in the presence of $\mathrm{TfOH}$ and diethyl azodicarboxylate (DEAD) (Scheme 8) [26]. This conversion occurred at room temperature, tolerated various functional groups and provided sulfides in good to excellent yields. In this conversion, DEAD reacted with disulfide to generate $\mathrm{N}$-sulfenylhydrazine and $\left[\mathrm{PhS}^{+}\right]\left[{ }^{-} \mathrm{OTf}\right]$ in the presence of $\mathrm{TfOH}$ via the cleavage of S-S bonds. $\left[\mathrm{PhS}^{+}\right]\left[{ }^{-} \mathrm{OTf}\right]$ was a very active intermediate, which can give a variety of sulfides when it was treated with carboxyl, hydroxyl, and sulfonamide-tethered alkenes, respectively. Moreover, aryl boronic acids and arenes were also suitable for this conversion. They were thiolated with disulfides to afford the corresponding sulfides when $\mathrm{BF}_{3} \bullet \mathrm{OEt}_{2}$ was used instead of TfOH. This reaction system was also successfully applied in the synthesis of diaryl selenides from diphenyl diselenides.

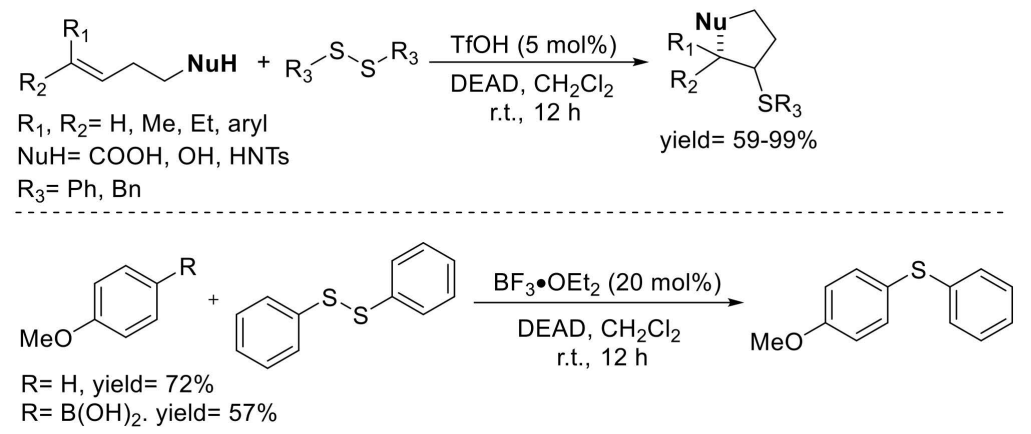

Scheme 8. C-S bond construction involving $\left[\mathrm{PhS}^{+}\right]\left[{ }^{-} \mathrm{OTf}\right]$.

\subsection{2. $\mathrm{C}\left(\mathrm{sp}^{2}\right)-\mathrm{S}$ Bond Formation with Disulfide}

In 2018, the Ouyang and Yang group found a very facile protocol to convert pentafluorobenzenes to dithiolated tetrafluorobenzenes (Scheme 9) [27]. The reaction occurred in the presence of $\mathrm{KOH}$ 
in DMF at room temperature, affording the corresponding dithiolated compounds. Mechanistic investigation indicated that the fluoro atom at 3-position of the pentafluorobenzene was initially thiolated by disulfide, and the $\mathrm{C}-\mathrm{H}$ bond was subsequently thiolated to give the dithiolated product. Based on this result, they further used 1-aryl-2,3,5,6- tetrafluorobenzenes as substrate to synthesize the unsymmetrical dithiolated products.

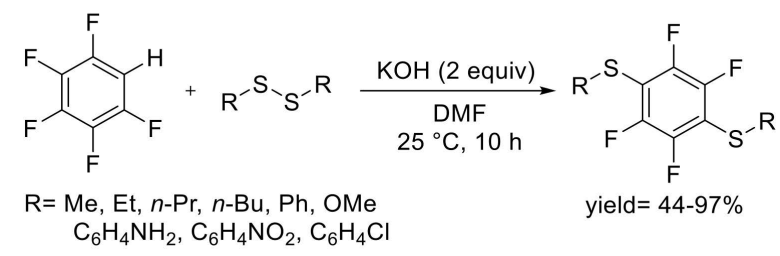

Scheme 9. Synthesis of dithiolated tetrafluorobenzenes.

In 2019, the Yotphan group reported a copper catalyzed regioselective C-H thiolation and thiocyanation of uracils using disulfide and $\mathrm{NH}_{4} \mathrm{SCN}$, respectively [28]. The reaction readily proceeded in the presence of catalytic $\mathrm{Cu}(\mathrm{OTf})_{2}$ and $\mathrm{K}_{2} \mathrm{~S}_{2} \mathrm{O}_{8}$ in acetonitrile (Scheme 10). A variety of functional groups were tolerated in the reaction system and good to excellent yields were obtained. Electron-rich diaryl disulfides were more favorable for this conversion than electron-deficient diaryl disulfides. For example, 1,2-bis(4-chlorophenyl)disulfane gave only $17 \%$ of the corresponding product. Control experiments indicated this conversion proceed through a radical process.

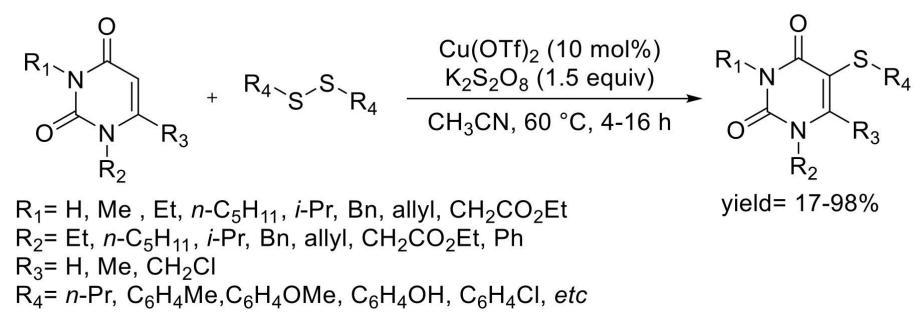

Scheme 10. C-H thiolation of uracils with disulfides.

\subsection{Thiol as Sulfenylation Source}

Thiol is an important sulfenylation reagent in the construction of sulfides. Traditional Ullmann typed C-S coupling reactions use aryl halides as substrates to couple with thiols in the presence of transition metal catalyst. Recent years have witnessed the fast development of direct C-S coupling of non-halide substrates with aryl/alkyl thiol.

\subsection{1. $\mathrm{C}\left(\mathrm{sp}^{3}\right)-\mathrm{S}$ Bond Formation with Thiol}

In 2018, the Lei group reported a radical-radical cross-coupling strategy for the construction of $\mathrm{C}\left(\mathrm{sp}^{3}\right)$-S bond using aryl thiols [29]. A series of $\alpha$-alkylthionitriles were synthesized from aryl thiols and isobutyronitrile in the presence of copper(II) salt as a catalyst (Scheme 11). The thiyl radical was generated from aryl thiol by oxidation by $\mathrm{Cu}(\mathrm{II})$ and stablized by $\mathrm{Cu}(\mathrm{I})$. It further coupled with isobutyronitrile radical generated from azobisisobutyronitrile. The reaction was carried out in the presence of $\mathrm{Cu}(\mathrm{OTf})_{2}$ as catalyst and 1,10-phen as ligand in 1,2-dichloroethane (DCE) at $80^{\circ} \mathrm{C}$. Both aryl thiols and heteroaryl thiols were smoothly converted into the corresponding C-S coupled products. Moreover, the cross-coupling product can be easily modified to valuable carboxylic acids, amides, and ketones. 


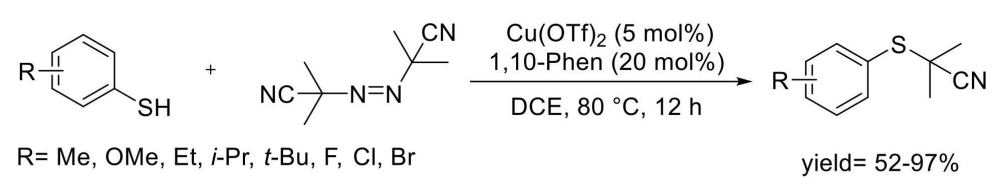

Scheme 11. C-S coupling reaction of aryl thiols and isobutyronitriles.

Diazo compound and diazo precursors such as hydrozne are also suitable for C-S coupling reaction with aryl thiols. In 2019, the Singh group reported an Eosin Y catalyzed, photoredox facilitated C-S bond formation for the synthesis of aryl benzyl sulfides from acetophenone hydrazines (Scheme 12) [30]. Acetophenone hydrazine coupled with aryl thiol to afford the corresponding sulfides in the presence of Eosin $\mathrm{Y}$ and $\mathrm{NaOH}$ under green LED $(530 \mathrm{~nm})$ irradiation. The addition of radical trap reagent 2,2,6,6-tetramethylpiperidine-1-oxyl (TEMPO) suppressed the transformation, indicating that the conversion was involved in a radical pathway.

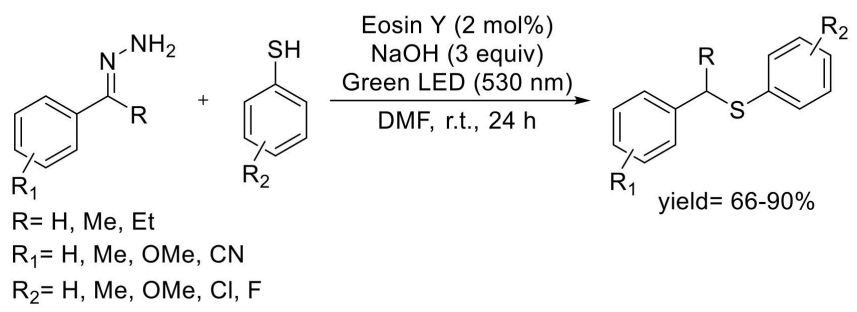

Scheme 12. C-S coupling reaction of acetophenone hydrazine and aryl thiol.

In 2020, the Huang and Baell group prepared TFMSA@SBA-15 by immobilizing trifluoromethanesulfonic acid on mesoporous silica SBA-15, and applied it as an efficient catalyst for the construction of C-C, C-O, C-N, and C-S bonds (Scheme 13) [31]. TFMSA@SBA-15 was effective in the coupling reaction of $\alpha$-diazoester and aryl thiol to afford the corresponding phenylsulfenyl phenylacetate esters. Moreover, the reaction system was attractive that the reaction occurred under solvent-free and room temperature condition. In addition, the reaction system was very efficient as the conversion can complete within 5-50 min.

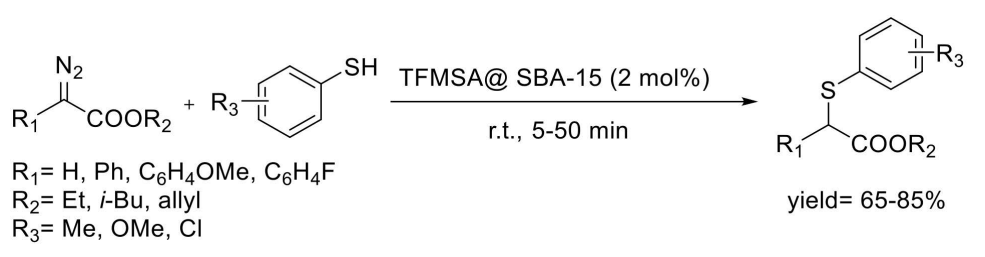

Scheme 13. C-S coupling reaction of diazo compounds and aryl thiols.

In 2018, the Zeng group developed a one-pot protocol for the synthesis of highly enantiopure benzylic thioethers, thioacetates, and sulfones through copper-catalyzed, ligand-free stereospecific C-S coupling reaction of aryl thiols and enantioenriched tertiary benzylic amines (Scheme 14) [32]. The developed protocol was featured by high enantio-selectivity, excellent yield and broad substrate scope. A great variety of benzylic amines and aryl thiols were well endured in this protocol. 


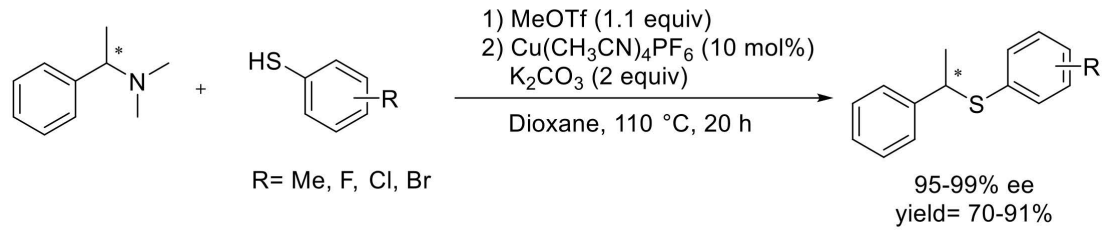

Scheme 14. Deaminative C-S coupling of benzyl amines and aryl thiols.

Dithioacetal is not only a traditional protecting group, but also an important precursor of ketones, alkyls, allkenes, and so on [33]. In 2018, the Wang group developed a facile protocol for the synthesis of dithioacetals through cascade C-S bond formation (Scheme 15) [34]. 3-Oxo-butanamides reacted with aryl thiols in the presence of $\mathrm{NaOH}$ and molecular oxygen in $n-\mathrm{PrCN}$ at $80{ }^{\circ} \mathrm{C}$, providing dithioamides in good to excellent yields. Moreover, this protocol can be also applied in the synthesis of diselenoacetal amides.

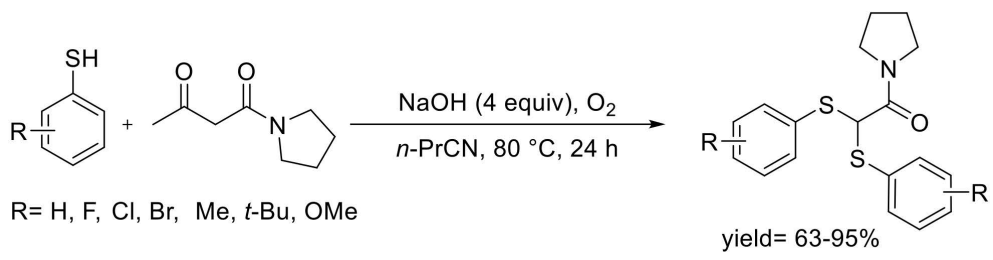

Scheme 15. Synthesis of dithioacetals from aryl thiols and 3-oxo-butanamide.

In 2018, the Lee group reported a novel dehydrative C-S bond formation for the synthesis of sulfides from 2-(hydromethyl)phenol and thiols in the presence of $I_{2}$ (Scheme 16) [35]. The reaction system was mild and efficient. The reaction occurred at room temperature and accomplished within $4 \mathrm{~h}$. It is noteworthy that both aryl thiol and aliphatic thiol were compatible in this protocol. In fact, in the competition experiment studies, slightly higher selectivity was observed with aliphatic thiols. Moreover, long chain aliphatic thiol can afford products in good yields in gram scale.

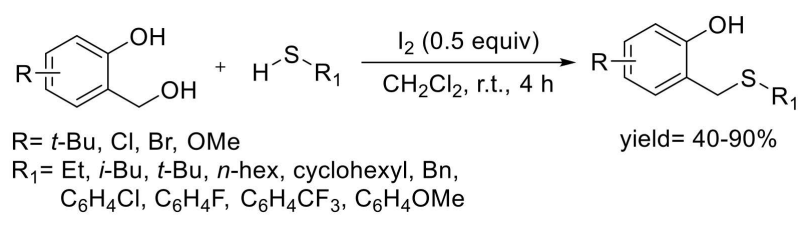

Scheme 16. Dehydrative C-S coupling of 2-(hydromethyl)phenols and thiols.

The Panda group reported another dehydrative C-S bond formation for the synthesis of triarylmethyl thioarenes from triaryl methanol and aryl thiols (Scheme 17) [36]. The reaction proceeded in the presence of indium (III) triflate as catalyst in THF at room temperature. This method allowed the reaction to complete within $15 \mathrm{~min}$ and give yields up to $76 \%$. This protocol was also successfully applied in the synthesis of tetraaryl methane from triaryl methanol and heteroarenes such as indole and furan. 


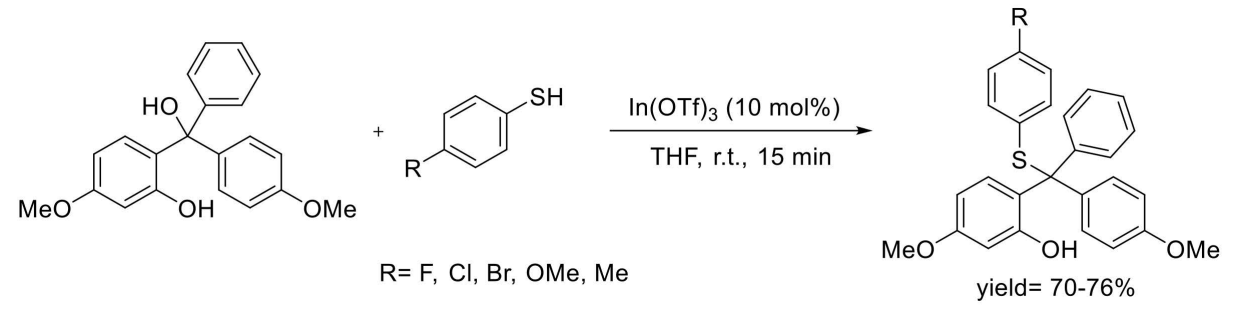

Scheme 17. Dehydrative C-S coupling of triaryl methanol and aryl thiols.

In 2018, the Yan and Yu group reported an oxidative disulfenylation/cyclization reaction of 2'-hydroxyacetophenones with thiophenols mediated by $\mathrm{TBAI} / \mathrm{K}_{2} \mathrm{~S}_{2} \mathrm{O}_{8}$ for the synthesis of functionalized 2,2-dithio-benzofuran-3(2H)-ones (Scheme 18) [37]. This protocol was featured by metal-free condition, satisfying yields and broad substrate scope. A variety of functional groups, including methoxyl, halogen, and amide, were well endured. The proposed mechanism indicated that the conversion underwent through two steps including disulfenylation and intramolecular cyclization.

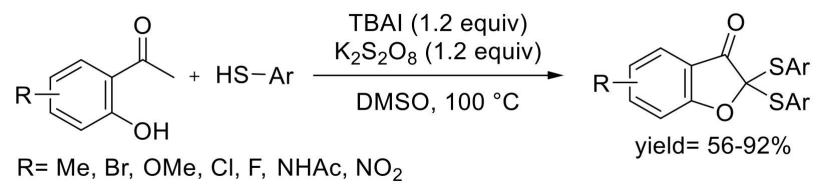

Scheme 18. Oxidative disulfenylation/cyclization reaction of $2^{\prime}$-hydroxyacetophenones.

In 2018, the Jang group found a novel synthetic method for allylic sulfides from $\alpha$-methylstyrenes and aryl thiols via direct C-S bond formation (Scheme 19) [38]. The reaction was carried out in the presence of 2,3-dichloro-5,6-dicyano-1,4-benzoquinone (DDQ) and 1,4-naphthoquinone (NQ) in DMA at $100{ }^{\circ} \mathrm{C}$. A variety of allylic hydrocarbons and aryl thiols were converted into the corresponding allylic sulfides in good yields. The mechanism investigation indicated that the radical process may be involved in this reaction and DDQ was employed to generate radicals.

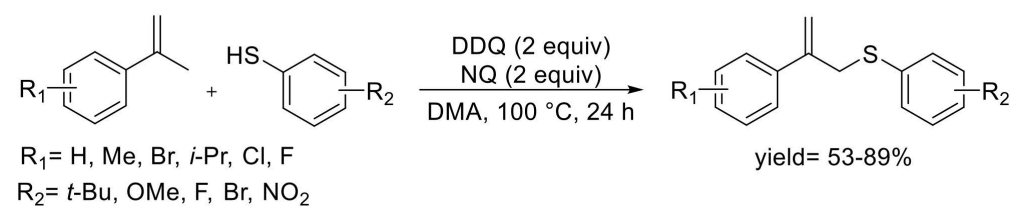

Scheme 19. Dehydrogenative C-S coupling of $\alpha$-methylstyrene and aryl thiol.

In 2019, the Xu group reported an iron-catalyzed C-H sulfenylation of oxindoles with aryl thiol for the direct synthesis of aryl sulfides (Scheme 20) [39]. The reaction was carried out in the presence of $\mathrm{FeCl}_{3}$ and $\mathrm{K}_{2} \mathrm{CO}_{3}$ in DMSO at $50^{\circ} \mathrm{C}$. This method exhibited excellent substrate endurance and generally gave good to excellent yields. Besides oxindoles, phenylacetamides, pyrazolones, phenylacetonitriles, and ethyl cyanoacetates were smoothly thiolated with aryl thiols to afford the corresponding sulfides in good yields. 


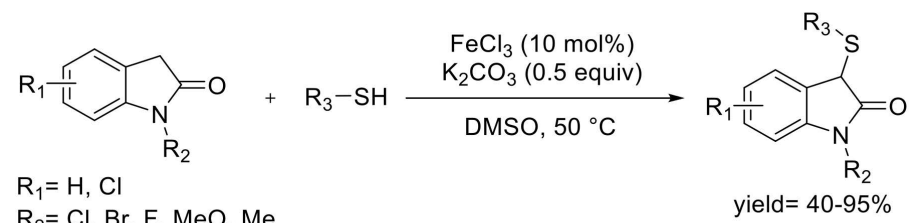

$\mathrm{R}_{2}=\mathrm{Cl}, \mathrm{Br}, \mathrm{F}, \mathrm{MeO}, \mathrm{Me}$

yield $=40-95 \%$

$\mathrm{R}_{3}=\mathrm{Ph}, \mathrm{C}_{6} \mathrm{H}_{4} \mathrm{Cl}, \mathrm{C}_{6} \mathrm{H}_{4} \mathrm{Me}, i$-pentyl, $n$-octyl

Scheme 20. $\mathrm{FeCl}_{3}$ catalyzed C-S coupling of oxindoles and thiols.

In 2019, the Gagnon group disclosed a direct S-cyclopropylation of thiophenols using tricyclopropylbismuth to synthesize aryl cyclopropyl sulfides (Scheme 21) [40]. The reaction was carried out in the presence of copper(II) acetate as the catalyst and pyridine as the base under mild conditions, providing the corresponding aryl cyclopropyl sulfides in moderate to good yields. A variety of functional groups including halogen, methoxyl, nitro, trifluoromethyl, and ester, were well tolerated.

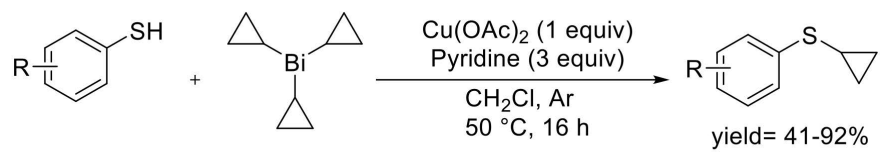

$\mathrm{R}=\mathrm{H}, \mathrm{Me}, \mathrm{F}, \mathrm{Cl}, \mathrm{Br}, \mathrm{OMe}, \mathrm{NO}_{2}, \mathrm{CF}_{3}, \mathrm{CO}_{2} \mathrm{Me}$

Scheme 21. Synthesis of aryl cyclopropyl sulfide from aryl thiol.

In 2019, the Xiao and Deng group reported a multicomponent reaction of $o$-phenylenediamines, thiophenols, and paraformaldehyde for the synthesis of $\mathrm{N}$-thiomethyl benzimidazoles via sequential C-N/C-S bond formation (Scheme 22) [41]. The reaction occurred in the presence of 4-aminodiphenylamine (4-ADPA) as base in a mixed solvent of 1,1,1,2-tetrachloroethane (TCE) and water at $130{ }^{\circ} \mathrm{C}$. This reaction provided the 1-phenylthiomethyl benzimidazoles in moderate to good yields. Moreover, the addition of different aldehydes led to the successful introduction of various functional groups at the 2-position of the benzimidazole.

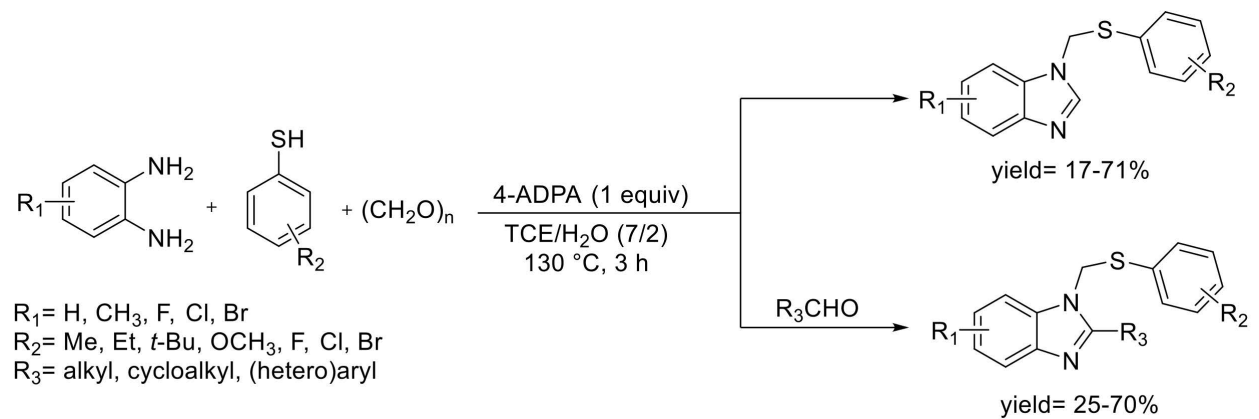

Scheme 22. Three-component reaction for the synthesis of 1-phenylthiomethyl benzimidazoles.

In 2019, the Wang group developed a unique C-S coupling reaction for the synthesis of $\alpha$-sulfenylated ketones from thiols and TEMPO. The reaction proceeded in the presence of $\mathrm{K}_{2} \mathrm{CO}_{3}$ in $\mathrm{N}, \mathrm{N}$-dimethylacetamide (DMA) at $150{ }^{\circ} \mathrm{C}$ (Scheme 23) [42]. A variety of aryl thiols and TEMPO analogues coupled smoothly to give the corresponding $\alpha$-sulfenylated ketones. In this transformation, TEMPO functioned as a C3 synthon. 


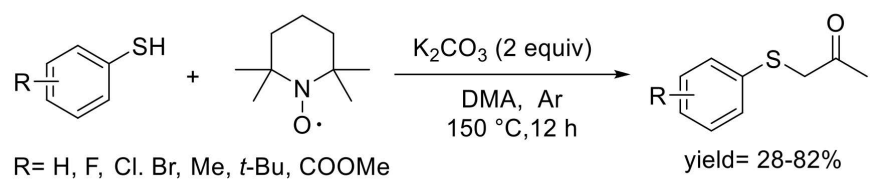

Scheme 23. C-S coupling reaction of aryl thiols and TEMPO.

\subsection{2. $\mathrm{C}\left(\mathrm{sp}^{2}\right)-\mathrm{S}$ Bond Formation with Thiol}

Decarboxylative C-S coupling reaction is an important strategy for the synthesis of sulfides. C-S bonds are readily constructed by the coupling reaction of carboxylic acid with aryl thiol, disulfides, sulfonyl hydrazides, sodium sulfinates, and sulfinic acids, respectively [43]. In 2016, the Hoover group reported a decarboxylative C-S bond formation for the synthesis of diaryl sulfides from 2-nitrobenzoic acid and aryl thiols (Scheme 24) [44]. The reaction was carried out at $140{ }^{\circ} \mathrm{C}$ in the presence of $\mathrm{CuI}$ as catalyst, 1,10-phen as ligand, $\mathrm{K}_{2} \mathrm{CO}_{3}$ as base and molecular oxygen as oxidant. Generally, good to excellent yields were obtained unless the 5-position of 2-nitrobenzoic acid was substituted. Heteroaryl thiols were converted into the corresponding sulfides in the same reaction system at $160{ }^{\circ} \mathrm{C}$. Moreover, treating 2-nitrobenzoic acid with aryl disulfide afforded the thiolated compounds as well. It is interesting that pentafluorobenzoic acid was dithiolated under the optimal condition.

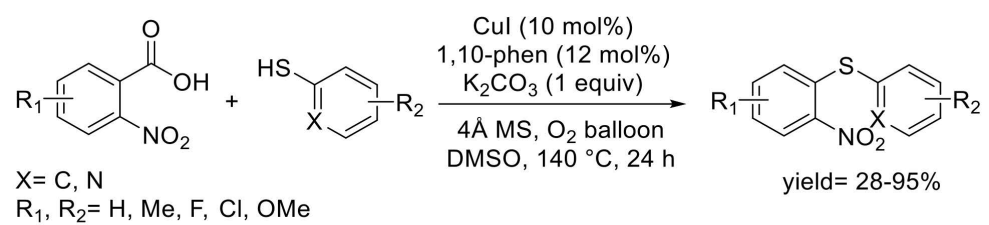

Scheme 24. Decarboxylative C-S coupling of 2-nitrobenzoic acid and aryl thiol.

In 2019, the Jafarpour group reported a simple procedure for the synthesis of unsymmetrical diaryl sulfides from arylhydrazines and aryl thiols (Scheme 25) [45]. The reaction proceeded at room temperature in the presence of $\mathrm{TBHP}, \mathrm{KI}$, and $\mathrm{Cs}_{2} \mathrm{CO}_{3}$ in water, providing the corresponding sulfides in good yields. In this reaction, TBHP was converted into several types of radicals in the presence of iodide. The radicals converted arylhydrazine and aryl thiol into phenyl radical and disulfide, respectively. The final C-S coupling reaction of phenyl radical and disulfide afforded the products.

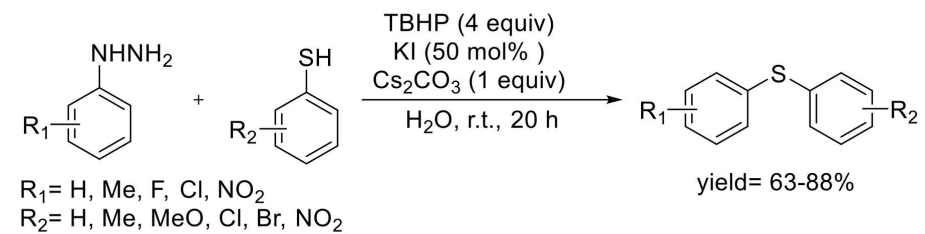

Scheme 25. C-S coupling reaction of arylhydrazines and aryl thiols.

In 2019, the Moghaddam group developed a coupling reaction of arylboronic acid with aryl or alkyl thiols to prepare unsymmetrical sulfides using $\mathrm{CoCuFe}_{2} \mathrm{O}_{4}$ nanoparticles as catalyst (Scheme 26) [46]. The reaction proceeded in the presence of $n-\mathrm{Bu}_{4} \mathrm{NOH}$ in DMF at $100{ }^{\circ} \mathrm{C}$. This protocol was also applied in the $\mathrm{C}-\mathrm{N}$ coupling reaction of arylboronic acid and anilines. 


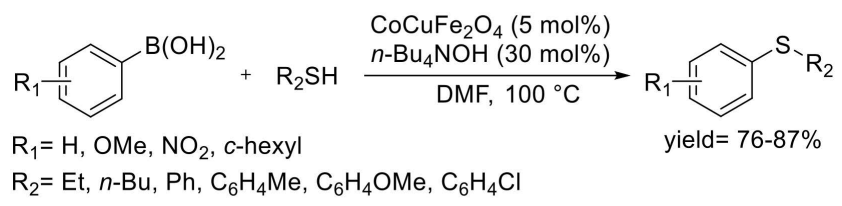

Scheme 26. $\mathrm{CoCuFe}_{2} \mathrm{O}_{4}$ nanoparticles catalyzed C-S coupling of aryl boronic acids and thiols.

In 2019, the Shankar group reported a $\mathrm{BCl}_{3}$ mediated one-pot debenzylation/sulfenylation reaction for the synthesis of sulfides. 3-((Benzyloxy) methyl) imidazo[1,2-a]pyridine was converted into sulfides in moderate to good yields (Scheme 27) [47]. This method was compatible with both aryl thiols and aliphatic thiols. The proposed mechanism indicated that the reaction proceeded through two steps including $\mathrm{BCl}_{3}$ mediated debenzylation and nucleophilic addition by thiols. In addition, thiols can be replaced by amine and alcohol to afford the corresponding amines and ethers, respectively.

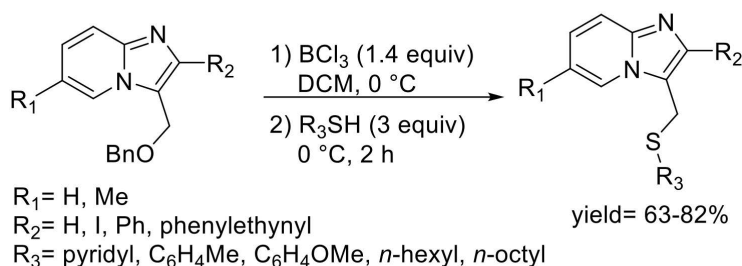

Scheme 27. Synthesis of sulfides from 3-((benzyloxy) methyl) imidazo[1,2-a]pyridines and thiols.

In 2018, the Das group developed a C-H sulfenylation of 4-quinolones with thiols or disulfides in the presence of NaI and TBHP in DMSO (Scheme 28) [48]. The reactions of aryl thiols without a substituent at the para-position provided excellent yields while the reactions with para-substituted aryl thiols gave lower yields (about 60\%).

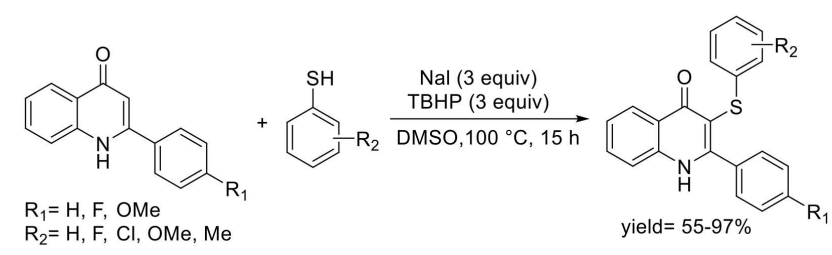

Scheme 28. C-H sulfenylation of 4-quinolones with aryl thiols.

In 2018, the Mal group developed a C-S coupling reaction of aryl thiols and benzenes bearing multiple methyl and/or methoxyl groups in the presence of PhI(OAc) $)_{2}$ in HFIP (Scheme 29) [49]. It is interesting that the product was controlled by the amount of $\mathrm{PhI}(\mathrm{OAc})_{2}$. When 1.0 equivalent of $\mathrm{PhI}(\mathrm{OAc})_{2}$ was used, diaryl sulfides were predominantly formed. However, when 3.0 equivalent of $\mathrm{PhI}(\mathrm{OAc})_{2}$ was used, the main products were diaryl sulfoxides. This reaction system was featured by a broad substrate scope. Functional groups, such as nitro, trifluoromethyl, halogen, ether, and formyl, were well endured. Moreover, aliphatic thiols were also tolerated in this protocol. 


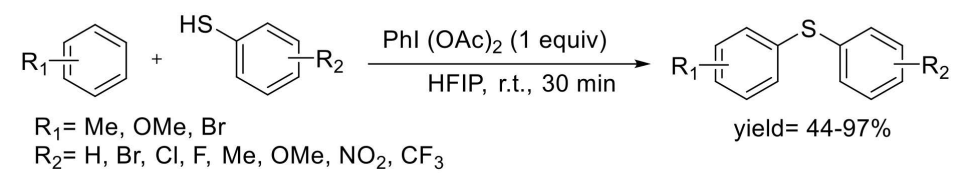

Scheme 29. $\mathrm{PhI}(\mathrm{OAc})_{2}$ mediated C-S coupling reaction of arenes and aryl thiols.

In 2019, the Yuan group reported a C-H thiolation strategy for the synthesis of aryl sulfide through the C-S coupling of thiols with functioned arenes (Scheme 30) [50]. The protocol employed cobalt(II) phthalocyanine-tetrasodium sulfonate (CoPcS) as catalyst and the reaction occurred in water in the atmosphere of oxygen. Both naphthol and naphthylamine coupled smoothly with aryl thiols to afford the corresponding diaryl sulfides in good to excellent yields. However, the coupling of naphthol with aliphatic thiols gave relatively low yields. A variety of functional groups such as methoxyl, amine, and halogen were well tolerated in this reaction system. In addition, $\mathrm{C}-\mathrm{H}$ bonds of indole and 2-phenylimidazo[1,2-a]pyridine were successfully thiolated with aryl thiols using the developed protocol.
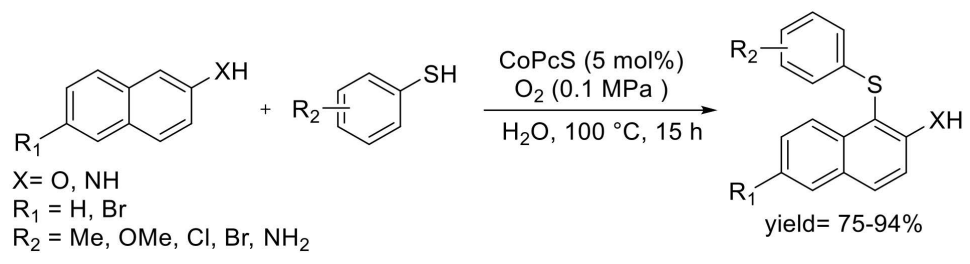

Scheme 30. C-S coupling reaction of aryl thiols and naphthols and naphthylamines.

In 2018, the Lei and Tang group reported an electrochemical oxidative C-H sulfenylation of imidazopyridines with thiols (Scheme 31) [51]. The conversion was achieved in an undivided electrolytic cell using methanol and acetonitrile as cosolvent. Both aryl thiols and aliphatic thiols reacted smoothly with imidazopyridines, providing di(hetero)aryl sulfides in moderate to good yields. They further found that this $\mathrm{C}-\mathrm{H}$ sulfenylation reaction can occur between imidazopyridines with diaryl disulfides.

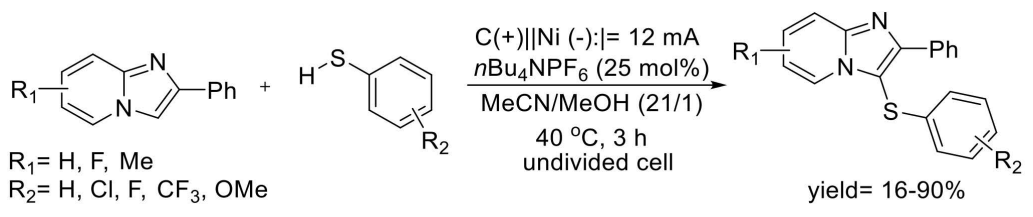

Scheme 31. Electrochemical C-H sulfenylation of imidazopyridines.

\subsection{Elemental Sulfur as Sulfenylation Source}

Elemental sulfur is an attractive sulfur source for the construction of C-S bond due to the low toxicity, stability, ready availability, odorless, and economical price [52]. In 2018, the Adimurthy group reported a copper catalyzed C-H disulfenylation of imidazo[1,2-a]pyridine for the synthesis of diaryl sulfides. Multiple components reaction of heteroarene, elemental sulfur, and aryl iodide afforded the disulfenylated products in good to excellent yields (Scheme 32) [53]. The reaction was carried out at $130{ }^{\circ} \mathrm{C}$ in the presence of $\mathrm{CuI}$ as catalyst and $\mathrm{KO} t$-Bu as a base in a mixed solvent of DMF and acetic acid. A variety of functional groups including halogen, methoxyl, boronic acid, and so on, were well 
tolerated in the developed reaction system. The mechanistic investigation showed this conversion underwent through two steps including the formation of aryl thiols from aryl iodides and elemental sulfur, and the C-H sulfenylation followed.

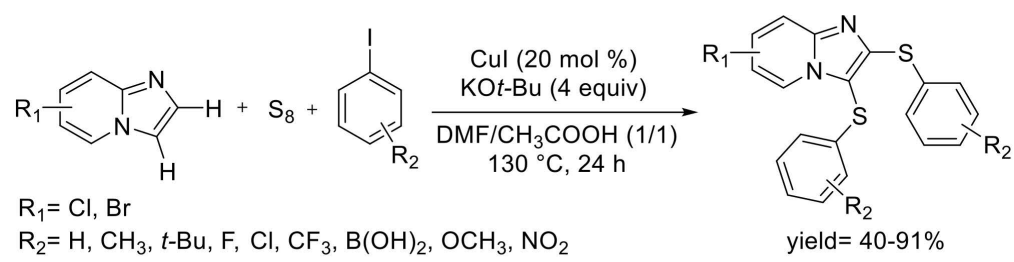

Scheme 32. Synthesis of disulfenylated imidazopyridines.

In 2018, the Zolfigol group reported a C-O bond activation/C-S coupling reaction for the synthesis of unsymmetrical diaryl sulfides from phenolic esters, aryl boronic acids and elemental sulfur using $\mathrm{NiFe}_{2} \mathrm{O}_{4}$ nanoparticles as a catalyst (Scheme 33) [54]. The reaction was compatible with several phenolic esters including acetates, triflates, and tosylates, and occurred in PEG2000 at $90{ }^{\circ} \mathrm{C}$ to afford the products in good to excellent yields. Moreover, the three-component reaction of phenolic esters, $\mathrm{Ph}_{3} \mathrm{SnCl}$ and sulfur also successfully afforded the unsymmetrical diaryl sulfides. They further found that the reaction of phenolic esters with sulfur can produce symmetrical diaryl sulfides in good to excellent yields at $120^{\circ} \mathrm{C}$ using anhydrous DMF as a solvent or under the solvent-free condition. In their paper, they provided a detailed comparison of their developed methods with the previously reported methods in view of required agents and starting materials/coupling partners.

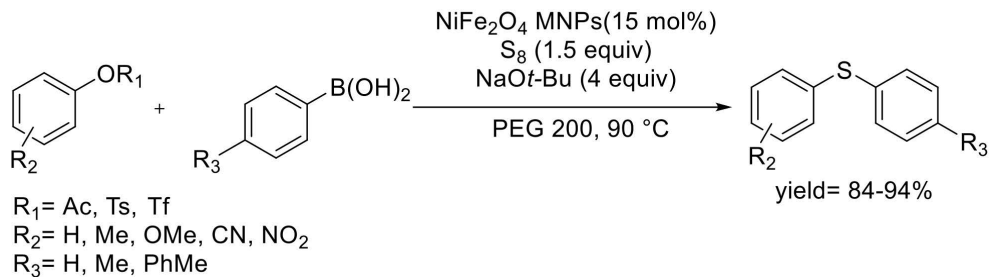

Scheme 33. C-S coupling reaction of phenolic esters and aryl boronic acids.

Later in 2019, the Rostami and Khakyzadeh group used phenols, sulfur, and aryl boronic acids as substrates and reported a $\mathrm{Pd} / \mathrm{Cu}$ dual-metal catalyzed one-pot $\mathrm{C}-\mathrm{O}$ bond activation/C-S coupling reaction for the synthesis of unsymmetrical diaryl sulfides (Scheme 34) [55]. Phenol was modified with sulfonyl or acetyl to afford the corresponding ester at the first step. Next, a synthesized novel $\mathrm{SiO}_{2}$ nanoparticles supported the Pd catalyst was used for C-O bond activation and the subsequent C-S bond formation. Compared to Zolfigol's work [54], this protocol allowed the reaction to proceed under milder conditions. The second step reaction was completed with $6 \mathrm{~h}$ at room temperature, and afforded the unsymmetrical diaryl sulfides in good to excellent yields. It is noteworthy that some sensitive functional groups such as formyl and cyano group were well tolerated in the reaction system.

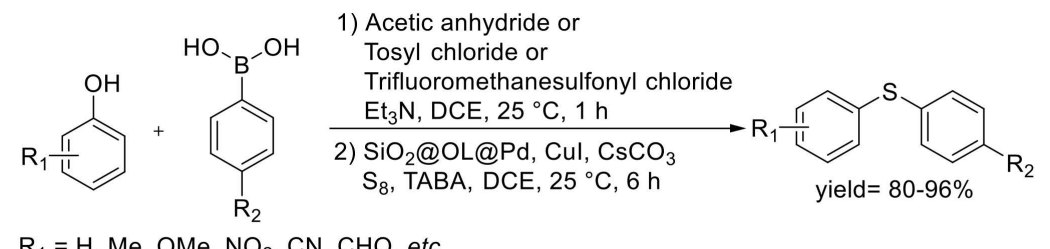

$\mathrm{R}_{2}=\mathrm{H}, \mathrm{Me}, \mathrm{NO}_{2}$

Scheme 34. Pd/Cu dual-metal catalyzed one-pot synthesis of diaryl sulfides. 


\subsection{Sulfonyl Derivative as the Sulfenylation Source}

Sulfonyl derivatives such as sulfonyl chloride and sodium sulfonates are employed as sulfenylation source. They are often used in a combination of reductant to afford disulfide as ultimate sulfenylation intermediate in the conversion.

In 2018, the Radosevich group developed an electrophilic sulfenylation reaction for the synthesis of sulfides from indoles and sulfonyl chlorides (Scheme 35) [56]. This conversion was catalyzed by a readily available phosphetane in conjunction with a hydrosilane terminal reductant to afford sulfenyl electrophiles, providing easy access to valuable trifluoromethyl-, perfluoroalkyl-, and heteroaryl derivatives. The reaction occurred at $40{ }^{\circ} \mathrm{C}$ in dioxane and accomplished within $12 \mathrm{~h}$. This protocol was further featured by broad substrate scope. Various functional groups, such as methoxyl, halogen, aldehyde, ester, and nitro group, were well tolerated.

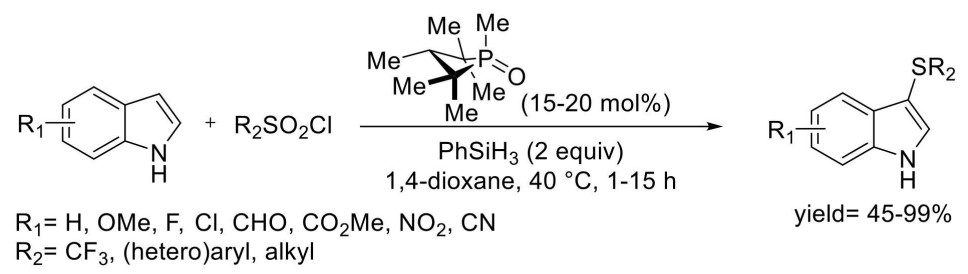

Scheme 35. Synthesis of sulfenylated indoles using sulfonyl chloride as a sulfenylative source.

In 2019, the Liu group reported a CuI-catalyzed C-S coupling reaction for the synthesis of diaryl sulfide from aryl boronic acid and arylsulfonyl chlorides (Scheme 36) [57]. This protocol used 1,10-phen as ligand and the conversion proceeded in the presence of $\mathrm{K}_{2} \mathrm{CO}_{3}$ and $\mathrm{PPh}_{3}$ in THF/DMSO (2:1) at $50{ }^{\circ} \mathrm{C}$. The reaction was completed within $4 \mathrm{~h}$. This method was featured by broad substrate scope for both arylboronic acids and arylsulfonyl chlorides. It is worth mentioning that the conversion required oxygen as the yield dramatically decreased when the reaction was carried out in the atmosphere of nitrogen. Using arylsulfonyl chlorides as sulfenylation source, this reaction system was successfully applied in the thiolation of acetylacetone and $\beta$-naphthol. In this reaction, arylsulfonyl chloride functioned as a disulfide precursor as it was converted into diaryl disulfide by treating it with $\mathrm{PPh}_{3}$. Disulfide subsequently formed a $\mathrm{Cu}(\mathrm{I})-\mathrm{S}$ complex and coupled with arylboronic acid to afford the corresponding diaryl thioether.

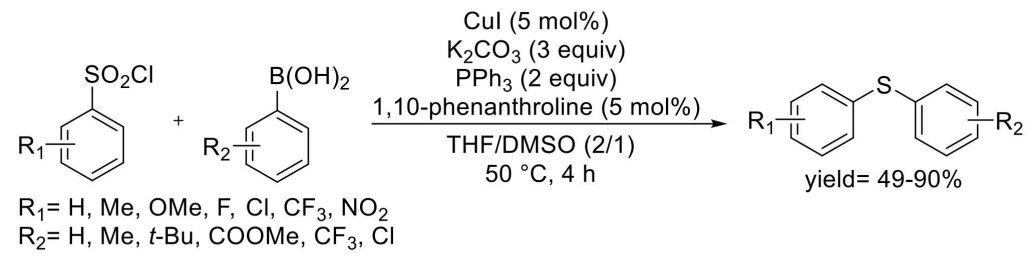

Scheme 36. Synthesis of diaryl sulfides from sulfonyl chlorides and aryl boronic acids.

The Zhao and Deng group reported a facile protocol for the sulfenylation of aliphatic ethers using sodium sulfonates in the presence of iodine, di-tert-butyl peroxide (TBP) and diethyl phosphite. The reaction occurred at $130^{\circ} \mathrm{C}$ in the air (Scheme 37) [58]. Initially, 1,4-dioxane was used as model substrate to react with sodium sulfinates, providing a variety of aryl sulfides in moderate to excellent yields. They further broaden the substrate scope to common cyclic and chained ethers. Moreover, sulfonyl hydrazides can also function as a thiolating reagent in this reaction system. In this conversion, TBP was converted to tert-butoxy radical under heating, and the radical grasped hydrogen from 1,4-dioxane to provide a povitol alkyl disulfide. On the other hand, sodium sulfonate was converted to disulfide by treating with iodine and diethyl phosphite. The radical intermediate coupled with disulfide to give the final product. 


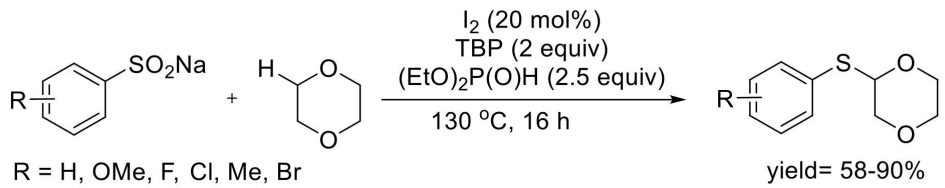

Scheme 37. Sulfenylation of 1,4-dioxane using sodium sulfonates.

\subsection{Other Sulfenylation Sources}

In 2018, the Li and Wen group reported a very facile and efficient protocol for the synthesis of 1,3-benzothiazepines from thioamides via dehydrogenative C-S bond formation (Scheme 38) [59]. In the presence of 4-F-HTIB (hydroxyl(4-fluorophenyl) iodotosylate), thioamides were readily converted to the corresponding 1,3-benzothiazepines in good to excellent yields. The conversion proceeded in HFIP at room temperature and were accomplished within $1 \mathrm{~min}$. It is very interesting that, when 4-methoxyphenethylthioamides were employed as starting materials, a new type of thiazaspiro[5.5]undecanones other than 1,3-benzothiazepines were afforded in good yields.

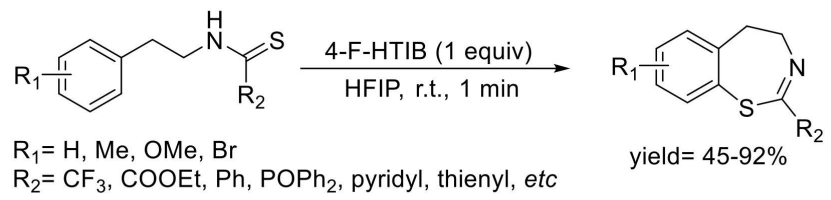

Scheme 38. Intramolecular thiolation of thioamides for the synthesis of 1,3-benzothiazepines.

In 2019, the Yamaguchi group developed a Pd-catalyzed synthesis of alkenyl thioether from thioester and $N$-tosyl hydrazones (Scheme 39) [60]. The reaction employed $\mathrm{Pd}(\mathrm{OAc})_{2}$ as catalyst, $\mathrm{P}(n-\mathrm{Bu})_{3}$ as ligand, $\mathrm{LiO} t-\mathrm{Bu}$ as base and occurred at $60^{\circ} \mathrm{C}$ in THF. In the developed reaction system, thioester was the best sulfur source because other sulfur-containing reagents such as thiophenol and diphenyl disulfide resulted in lower yield and poor reaction selectivity. This method exhibited broad substrate scope as it was compatible with various functional groups, such as methoxyl, halogen, ester, amide, trifluoromethyl, etc.

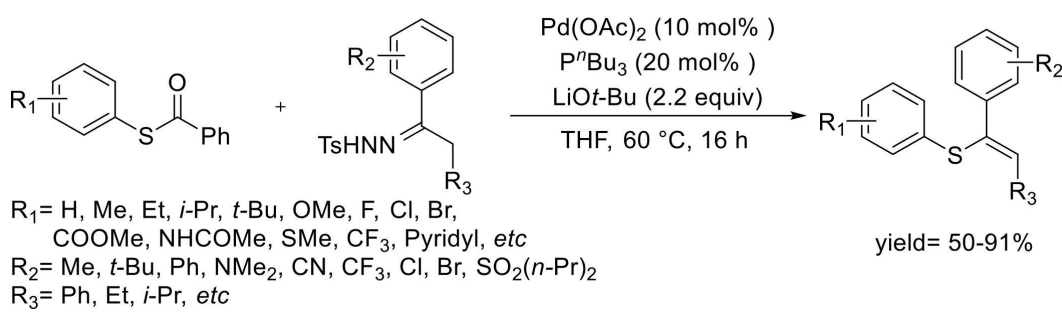

Scheme 39. Synthesis of aryl alkenyl sulfides from thioesters and $N$-tosyl hydrazones.

In 2020,the Singh group reported an iodine-catalyzed synthesis of 3-arylthioindoles from indoles employing a 1-aryltriazene/ $\mathrm{CS}_{2}$ combination as the sulfenylation source (Scheme 40) [61]. The reaction was performed in ethanol at $70{ }^{\circ} \mathrm{C}$. The corresponding diaryl sulfides were obtained in good to excellent yields. Broad substrate scope was exhibited by this protocol as functional groups including methoxyl, halogen, cyan, trifluoromethyl, and nitro group were well tolerated. Moreover, this protocol was also applied in the sulfenylation of trimethoxybenzene and 2-hydroxynaphthalene, yielding the corresponding sulfides. 


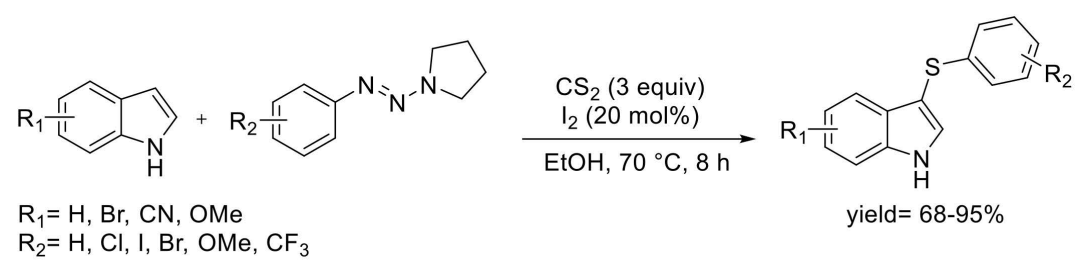

Scheme 40. Synthesis of 3-arylthioindoles from indoles, 1-aryltriazene, and $\mathrm{CS}_{2}$.

\subsection{Trifluoromethylthio Reagents as Sulfenylation Sources}

Molecules containing trifluoromethylthio group are a unique type of sulfides and have attracted extensive attention because they have found wide application in pharmaceuticals, agrochemicals, and materials. Due to the strong electron-withdrawing effect and hydrophobic property, trifluoromethyl sulfides are important building blocks in drug design. The traditional method for the synthesis of trifluoromethylthiolated compounds is the nucleophilic trifluoromethylthiolation of aryl halides with trifluoromethylthiolated metals, such as $\mathrm{Hg}\left(\mathrm{SCF}_{3}\right), \mathrm{Ag}\left(\mathrm{SCF}_{3}\right), \mathrm{Cu}\left(\mathrm{SCF}_{3}\right), \mathrm{Cs}\left(\mathrm{SCF}_{3}\right)$, and $(b p y) \mathrm{Cu}\left(\mathrm{SCF}_{3}\right)$ [62]. In recent years, several novel organic trifluoromethylthio surrogates have been developed and enabled the trifluoromethylthiolation to occur to non-halide substrates.

In 2016, the Hopkinson and Glorius group reported the first visible-light-promoted radical trifluoromethylthiolation of styrenes using 2-((trifluoromethyl)thio)isoindoline-1,3-dione as trifluoromethylthio source (Scheme 41) [63]. The reaction proceeded in the presence of $f a c$ - $\left[\operatorname{Ir}(p p y)_{3}\right]$ as photocatalyst and $n \mathrm{Bu}_{4} \mathrm{NBr}$ as an activator in acetonitrile at room temperature. A variety of styrenes were smoothly converted into the corresponding trifluoromethylthiolated products in satisfying yields.

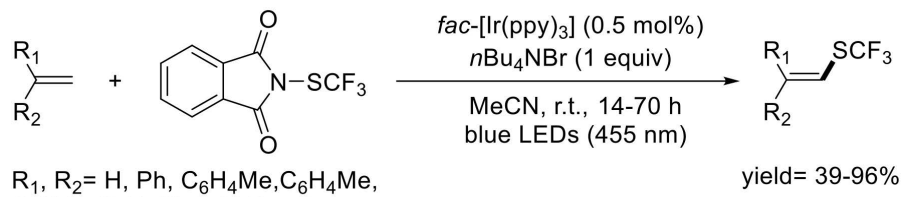
$\mathrm{C}_{6} \mathrm{H}_{4} \mathrm{~F}, \mathrm{C}_{6} \mathrm{H}_{4} \mathrm{Cl}, \mathrm{C}_{6} \mathrm{H}_{4} \mathrm{Br}$, etc

Scheme 41. $f a c-\left[\operatorname{Ir}(\mathrm{ppy})_{3}\right]$ catalyzed trifluoromethylthiolation of alkenes.

In 2017, the $\mathrm{Xu}$ group found a novel $\mathrm{SCF}_{3}$ source, S-trifluoromethyl 4-methylbenzenesulfonothioate, and developed a dual gold and photoredox catalyzed reaction for the phenylsulfonyl-trifluoromethylthio-1,2-difunctionalization of alkenes (Scheme 42) [64]. $S$-trifluoromethyl 4-methylbenzenesulfonothioate functioned as bifunctional reagent responsible for both trifluoromethylthiolative and phenylsulfonylative reagent. Alkenes including styrenes, internal alkenes, and dienes were converted into the corresponding products in the presence of IPrAuCl, $\mathrm{AgSbF}_{6}$, and $\mathrm{Ru}(\mathrm{bpy})_{3} \mathrm{Cl}_{2}$ in DCE at room temperature under irradiation with $100 \mathrm{~W}$ blue LED at the $\mathrm{N}_{2}$ atmosphere. A series of functional groups, such as ester, cyano, triuoromethyl, and halogen, were well tolerated under the optimized reaction condition. Moreover, it is noteworthy that the reaction system was also compatible with $\mathrm{PhSO}_{2} \mathrm{SR}(\mathrm{R}=$ aryl or alkyl), affording various phenylsulfonyl sulfides.

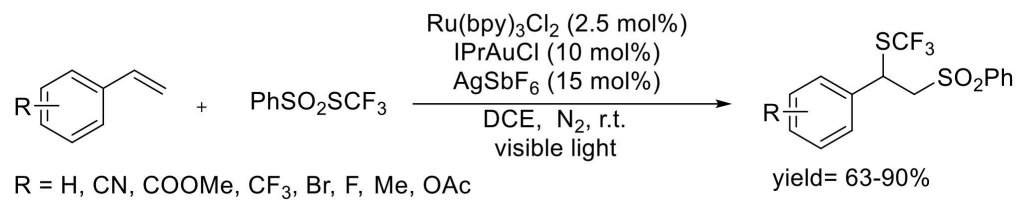

Scheme 42. Synthesis of benzyl trifluoromethyl sulfides from styrenes. 
In 2017, the Dagousset and Magnier group reported the visible light driven synthesis of trifluoromethylthiol-substituted oxindoles from $N$-methyl- $N$-phenylmethacrylamides using $\mathrm{N}$ - trifluoromethylthiosaccharin as an $\mathrm{SCF}_{3}$ radical precursor (Scheme 43) [65]. This conversion employed $\operatorname{Ir}(\mathrm{ppy})_{3}$ as photocatalyst and was carried out at room temperature under the irradiation of blue LEDs. Using different alkenes as substrates, the same reaction system led to the synthesis of $\mathrm{SCF}_{3}$-containing oxindole, trifluoromethylthiolated isoquinolinediones, and diarylethyl trifluoromethyl sulfides in good yields. The reaction system was compatible with lots of functional groups, such as halogen, cyan group, acetyl, ester, and BocNH.

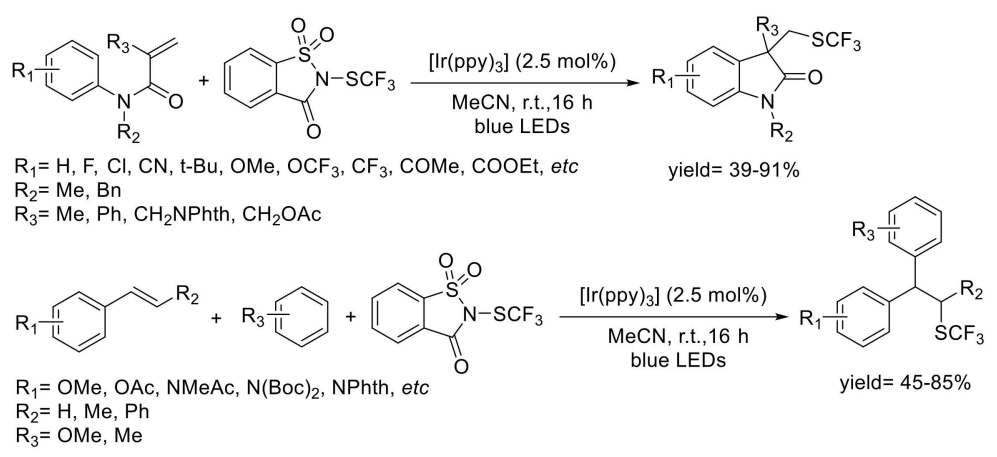

Scheme 43. Visible light driven synthesis of trifluoromethylthiol-substituted oxindoles.

Later in 2018, the Zhao group applied S-trifluoromethyl 4-methylbenzenesulfonothioate as $\mathrm{SCF}_{3}$ radical precursor for the same conversion (Scheme 44) [66]. The reaction occurred in the presence of $\mathrm{AgF}$ and $\mathrm{K}_{2} \mathrm{~S}_{2} \mathrm{O}_{8}$ in $\mathrm{DMSO}$ at $20^{\circ} \mathrm{C}$. The mechanistic studies indicated that $\mathrm{AgSCF}_{3}$ was generated from $S$-trifluoromethyl 4-methylbenzenesulfonothioate and $\mathrm{AgF}$, and $\mathrm{SCF}_{3}$ radicals were subsequently formed by the oxidation with $\mathrm{K}_{2} \mathrm{~S}_{2} \mathrm{O}_{8}$.

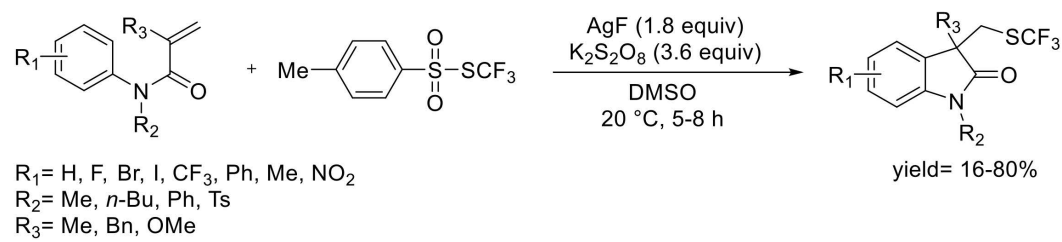

Scheme 44. Synthesis of trifluoromethylthiol-substituted oxindoles from $N$-phenylmethacryl amides.

\section{Synthesis of Sulfoxides via C-S Bond Construction}

In 2018, the Bolm group reported a transition-metal-free arylation of $\beta$-sulfinyl esters with diaryliodonium salts to provide a wide range of $S$, S-diaryl and S-alkyl S-aryl sulfoxides (Scheme 45) [67]. The reaction occurred at room temperature in the presence of $\mathrm{KOH}$ in the cosolvent of toluene and water. In this process, sulfenate anion was generated from $\beta$-sulfinyl esters and form a C-S bond with aryl group of diaryliodonium. In general, this protocol provided the corresponding diaryl sulfoxides in good to excellent yields. The yields decreased when alkyl sulfinyl esters or heteroaryliodonium were used as substrates.

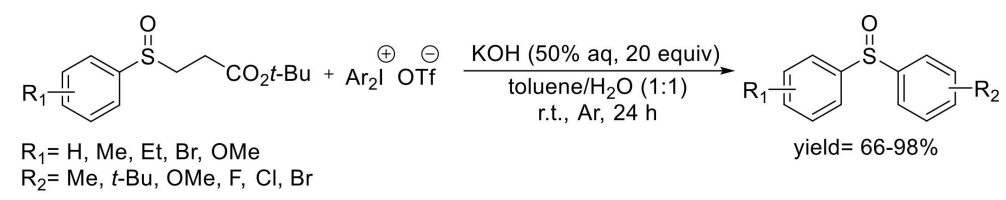

Scheme 45. Synthesis of sulfoxides from $\beta$-sulfinyl esters. 
In 2018, the Wang group found a facile protocol for the synthesis of diaryl sulfoxides and $m$-arylthio sulfones from arylsulfinic acids and dimethoxybenzenes via $\mathrm{BF}_{3}$ mediated $\mathrm{C}-\mathrm{S}$ bond formation (Scheme 46) [68]. The reaction easily proceeded in $\mathrm{CH}_{2} \mathrm{Cl}_{2}$ without any other additives. The reaction temperature was very important for the reaction selectivity. The diaryl sulfones were predominantly afforded when the reaction was carried out at $30^{\circ} \mathrm{C}$. Diaryl sulfones were further sulfenylated by arylsulfinic acid to provided $m$-arylthio sulfones at $80^{\circ} \mathrm{C}$.
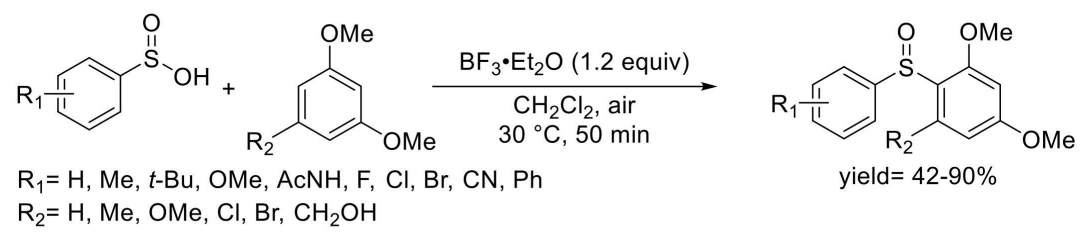

$\mathrm{R}_{1}=\mathrm{H}, \mathrm{Me}, \mathrm{t}-\mathrm{Bu}, \mathrm{OMe}, \mathrm{AcNH}, \mathrm{F}, \mathrm{Cl}$
$\mathrm{R}_{2}=\mathrm{H}, \mathrm{Me}, \mathrm{OMe}, \mathrm{Cl}, \mathrm{Br}, \mathrm{CH}_{2} \mathrm{OH}$

yield $=42-90 \%$

Scheme 46. Synthesis of diaryl sulfoxides from arylsulfinic acids and arenes.

\section{Synthesis of Sulfones via C-S Bond Construction}

Sulfonylhydrazides and sulfonylhydrazones are frequently used as sulfonyl source for the synthesis of sulfones via C-S bond formation. In 2016, the Zhao group reported a denitrogenative C-S bond formation for the synthesis of disubstituted methylsulfones from sulfonylhydrazones (Scheme 47) [69]. Sulfonylhydrazones were readily prepared from ketones and sulfonyl hydrazides. Sulfonylhydrazones decomposed to release nitrogen and afford the methylsulfones in the presence of $\mathrm{FePcCl}$ in dioxane at $80^{\circ} \mathrm{C}$. Using this protocol, methylsulfones were obtained in good to excellent yields.

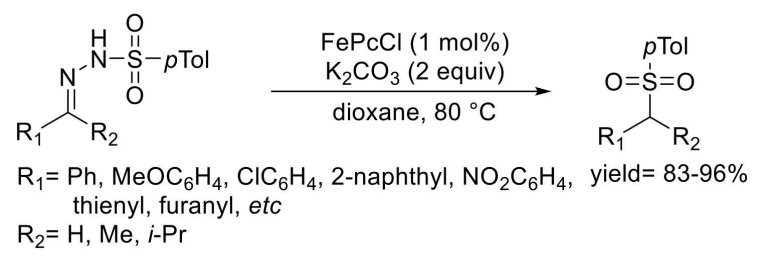

Scheme 47. Denitrogenative synthesis of disubstituted methylsulfones from sulfonylhydrazones.

In 2018, the Kleij and Yang group used $N$-sulfonylhydrazone as sulfonyl source and reported a synthetic method for allylic sulfones via decarboxylative C-S bond formation (Scheme 48) [70]. Vinylethylene carbonate was used as substrate. C-S coupling reaction occurred to afford allylic sulfones at $80^{\circ} \mathrm{C}$ in acetonitrile in the presence of $\mathrm{Pd}_{2}(\mathrm{dba})_{3}$ as catalyst and $\mathrm{K}_{2} \mathrm{CO}_{3}$ as base. It is worth noting that the products were obtained with high regio-selectivity. A wide range of functional groups were tolerated under the optimal condition. Moreover, changing the catalyst from $\mathrm{Pd}_{2}(\mathrm{dba})_{3}$ to $\mathrm{Pd}\left(\mathrm{PPh}_{3}\right)_{4}$ predominantly afforded the allylic hydrazones as products. The developed protocol was successfully applied in the functionalization of some biologically important scaffolds.

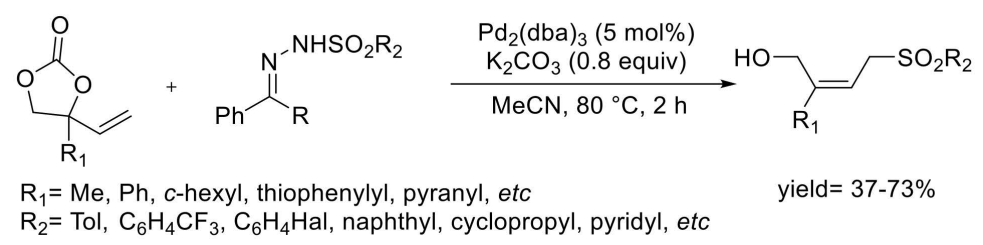

Scheme 48. Decarboxylative C-S bond formation between vinylethylene carbonate and $N$-sulfonylhydrazone. 
In 2018, the Wang and Ji group reported a $\mathrm{Cu}(\mathrm{II}) / \mathrm{Ag}(\mathrm{I})$-catalyzed cascade reaction for the synthesis of 2-aryl-3-sulfonyl substituted quinoline from sulfonyl hydrazine with anthranils (Scheme 49) [71]. It is interesting that new C-C, C-N and C-S bonds were constructed in one step. The conversion proceeded at $110^{\circ} \mathrm{C}$ in the presence of $\mathrm{Cu}(\mathrm{OAc})_{2}$ and $\mathrm{AgOTf}$ in DCE without any other additives. No product was observed in the absence of either $\mathrm{Cu}(\mathrm{OAc})_{2}$ or AgOTf. Phenyl sulfonyl hydrazines gave moderate yields while heteroaryl sulfonyl hydrazines were not favorable for this conversion.

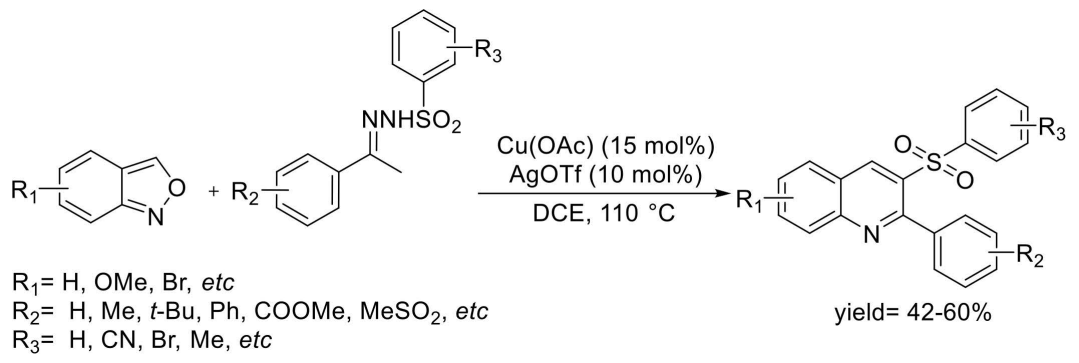

Scheme 49. Synthesis of 2-aryl-3-sulfonyl substituted quinoline using sulfonyl hydrazone as sulfonyl source.

In 2018, the Liang group developed a novel protocol for the synthesis of 2-sulfonated pyrrolo[1,2-a]indoles using toluenesulfonyl hydrazide as a sulfonyl reagent (Scheme 50) [72]. $\mathrm{N}$-propargyl-substituted indoles were used as substrates and the reaction occurred in the presence of $\mathrm{Cu}\left(\mathrm{NO}_{3}\right)_{2} \bullet 3 \mathrm{H}_{2} \mathrm{O}$ as catalyst, TBHP and AgTFA in DCE at $90{ }^{\circ} \mathrm{C}$. Toluenesulfonyl hydrazide proved as a good tosyl source while sodium tosylate and tosyl chloride were not able to furnish this conversion under the standard condition. The proposed mechanism indicated that the reaction of sulfonyl hydrazide with tert-butoxyl or tert-butylperoxyl radical generated from TBHP gave the sulfonyl radical. Then, an addition reaction of the sulfonyl radical occurred to the alkynyl moiety give the vinyl radical. The followed 1,2-aryl migration cascade process produced the final product.

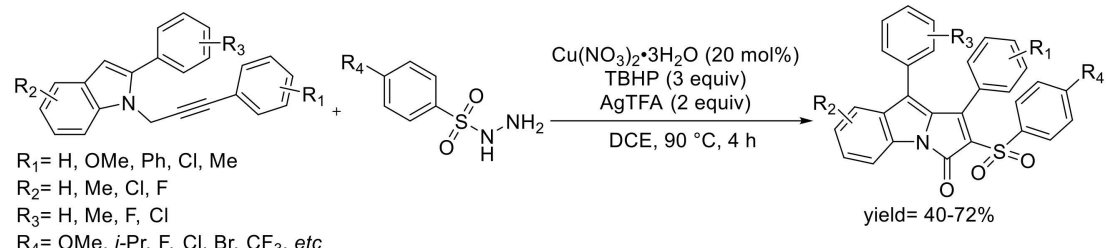

Scheme 50. Synthesis of 2-sulfonated pyrrolo[1,2-a]indoles using sulfonyl hydrazine as a sulfonyl source.

In the same year, the Liu and Zhu group used the same sulfonylation reagent and found a new method for the synthesis of diaryl methylsulfones via sulfonylation of para-quinone methides (Scheme 51) [73]. The reaction occurred smoothly in the cosolvent of ethanol and water at $50{ }^{\circ} \mathrm{C}$ without the use of any catalyst. This protocol was further featured by broad substrate scope and good to excellent yields.

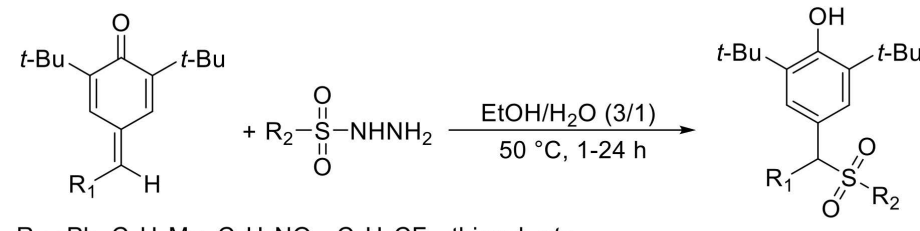

$\mathrm{R}_{1}=\mathrm{Ph}, \mathrm{C}_{6} \mathrm{H}_{4} \mathrm{Me}, \mathrm{C}_{6} \mathrm{H}_{4} \mathrm{NO}_{2}, \mathrm{C}_{6} \mathrm{H}_{4} \mathrm{CF}_{3}$, thienyl, etc

$\mathrm{R}_{2}=\mathrm{Et}, n-\mathrm{Bu}, \mathrm{Bn}, \mathrm{Ph}, \mathrm{C}_{6} \mathrm{H}_{4} \mathrm{Me}, \mathrm{C}_{6} \mathrm{H}_{4} \mathrm{NO}_{2}, \mathrm{C}_{6} \mathrm{H}_{4} \mathrm{CF}_{3}$, thienyl, etc

yield $=80-96 \%$

Scheme 51. C-H sulfonylation of para-quinone methides with sulfonyl hydrazides. 
Later in 2019, the Du group further applied sulfonyl hydrazides as sulfonyl reagent in the one-pot synthesis of 3-sulfonylbenzofurans from o-hydroxybenzyl alcohols (Scheme 52) [74]. This reaction system was compatible with a variety of functional groups and provided the diaryl sulfones in good yields. It is noteworthy that the 3-sulfonylbenzofurans can be readily elaborated to diaryl thioethers, diarylmethanones, and Suzuki coupling products.

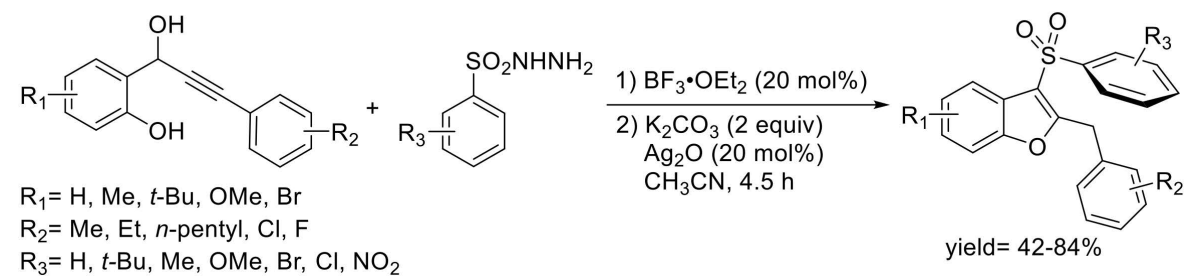

Scheme 52. Synthesis of 3-sulfonylbenzofurans from o-hydroxybenzyl alcohols and sulfonyl hydrazines.

In 2017, the Reiser group reported a temperature controlled selective C-S or C-C formation from heteroarenes and aryl sulfonyl chloride for the synthesis of diaryl sulfones or aryl heteroarenes (Scheme 53) [75]. The reaction employed $f a c\left[\operatorname{Ir}(\text { ppy })_{3}\right]$ as photocatalyst, and was carried out in anhydrous acetonitrile under the irradiation of $\mathrm{LED}_{455}$. Heteroarenes, such as thiophene, pyrrole, and indole were well tolerated in this conversion. It is very interesting that the reaction at room temperature gave diaryl sulfones as a product, but the reaction at $60^{\circ} \mathrm{C}$ provided aryl heteroarenes as the product.

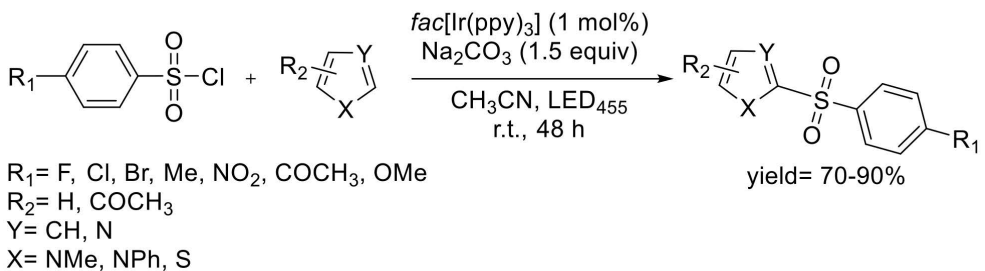

Scheme 53. C-H sulfonylation of heteroarenes with phenylsulfonyl chloride.

In 2019, the Deng group developed a three-component reaction for the preparation of diarylmethyl sulfones from aldehydes, arenes, and sodium sulfinates via tandem C-C/C-S bond formation (Scheme 54) [76]. The reaction proceeded at $60{ }^{\circ} \mathrm{C}$ in water in the presence of ion exchange resin amberlyst 15. Compared with previously reported methods, this protocol was featured by simple procedure, no requirement of metal catalysts and use of recyclable heterogeneous catalyst, and organic solvent-free condition, providing a green method to synthesize diarylmethyl sulfones.

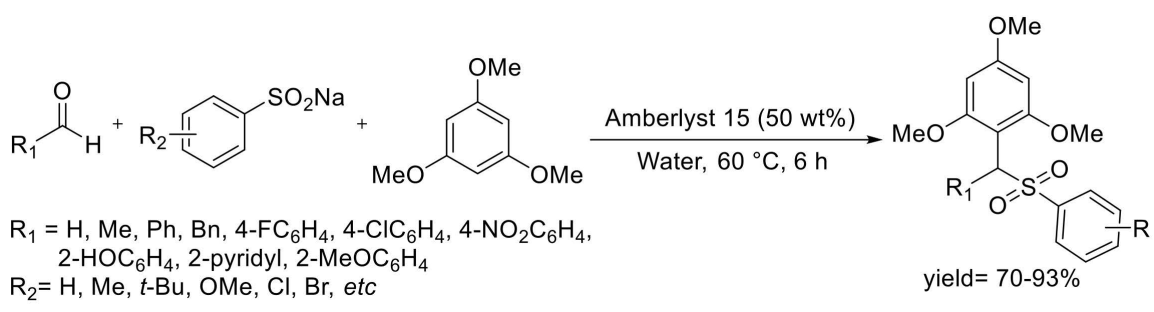

Scheme 54. Three-component reaction for the preparation of diarylmethyl sulfones.

In 2017, the Willis group developed a direct photoinduced sulfonylation of $N$-alkylated anilines with sodium sulfinates using an iridium complex as catalyst (Scheme 55) [77]. The reactions were carried out under the irradiation of blue LEDs in the presence of $\mathrm{Bu}_{4} \mathrm{NHSO}_{4}$ and $\mathrm{K}_{2} \mathrm{~S}_{2} \mathrm{O}_{8}$ in the cosolvent of acetonitrile and water. This protocol exhibited regio-selectivity and provided good overall 
yields. Very broad substrate scope and good functional group endurance were observed with this protocol. Both alkylsulfinates and arylsulfinates were well tolerated. Moreover, they showed the produced sulfones were readily converted into diverse derivatives. The mechanism investigation indicated that oxidation of the aniline and the sullfinate salt by the iridium catalytic cycle afforded aniline radical cation and sulfonyl radical, respectively. The two radicals coupled to provide the sulfone product via C-S bond formation.

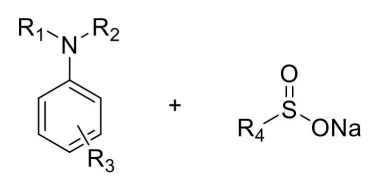

$\mathrm{R}_{1}, \mathrm{R}_{2}=\mathrm{Me}, \mathrm{Et}, \mathrm{Ph}$, etc $\mathrm{R}_{3}=\mathrm{Me}, s-\mathrm{Bu}, t-\mathrm{Bu}, \mathrm{CH}_{2}$ $\mathrm{OMe}, \mathrm{OH}, \mathrm{NMe}_{2}, \mathrm{NHAc}, \mathrm{Cl}, \mathrm{Br}$, I, etc $\mathrm{R}_{4}=\mathrm{Me}, \mathrm{i}-\mathrm{Pr}$, cyclopropyl, $\mathrm{C}_{6} \mathrm{H}_{4} \mathrm{Me}, \mathrm{C}_{6} \mathrm{H}_{4} \mathrm{OMe}, \mathrm{C}_{6} \mathrm{H}_{4} \mathrm{~F}$, etc

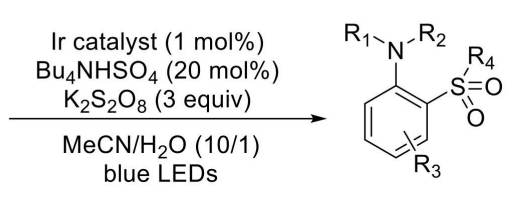

yield $=17-85 \%$

Scheme 55. Photoinduced sulfonylation of $N$-alkylated anilines with sodium sulfinates.

In 2019, the Waldvogel group reported an electrochemical sulfonylation of arenes containing electron donating group using sodium sulfinates as a sulfonylation reagent (Scheme 56) [78]. The reaction employed BDD as electrode and $\operatorname{HFIP}(1,1,1,3,3,3$-hexafluoropropan-2-ol)/water as cosolvent. The sulfonates were used as both coupling component and supporting electrolyte. The arenes containing electron donating groups, such as methoxyl, methyl, dimethylamino and acetylamino, were readily sulfonated with either sodium arylsulfinates or sodium alkylsulfinates.

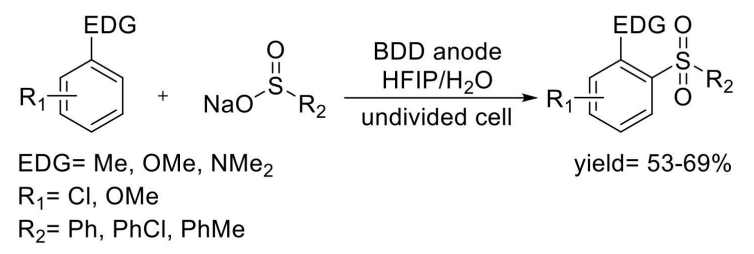

Scheme 56. Electrochemical sulfonylation of arenes with sodium sulfinates.

In 2018, the Song group developed the first example of $\mathrm{Rh}(\mathrm{II}) /$ phosphine-cocatalyzed reaction system for the synthesis of dithioketals from diazo compounds through simultaneous construction of two different C-S Bonds (Scheme 57) [79]. Diazoacetate reacted with $S$-methyl benzenesulfonothioate at room temperature in the presence of $\mathrm{Rh}_{2}(\mathrm{OAc})_{4}$ and dppp in DCE, providing dithioketal derivatives in moderate to good yields.

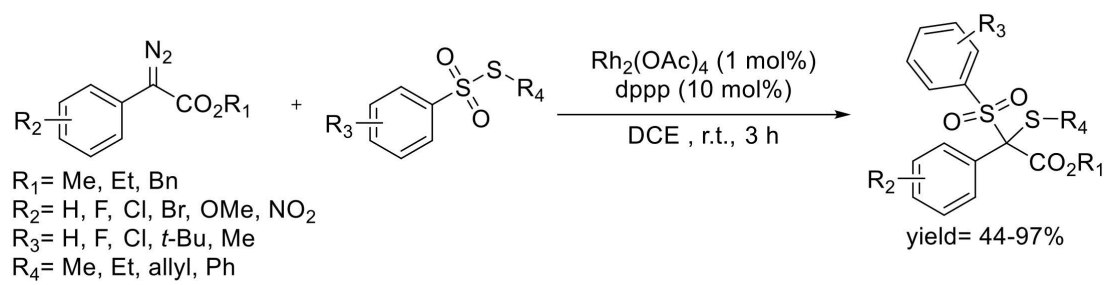

Scheme 57. Synthesis of dithioketals from diazo compounds.

In 2020, the Reddy group developed an interesting strategy for the synthesis of benzyl disulfanylsulfones from $S$-benzyl thiosulfonates via phenylboronic acid catalyzed tandem construction of S-S and C-S Bonds (Scheme 58) [80]. The reaction occurred in the presence of $\mathrm{K}_{2} \mathrm{CO}_{3}$ in $\mathrm{PhCl}$ at $90^{\circ} \mathrm{C}$, providing the corresponding benzyl disulfanylsulfones in good to excellent yields. 


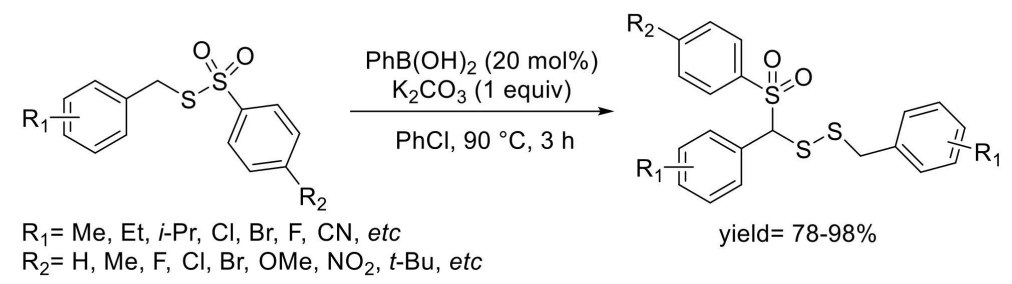

Scheme 58. Synthesis of benzyl disulfanylsulfones from S-benzyl thiosulfonates.

\section{Conclusions and Prospects}

The research on the synthetic methods for organosulfur compounds is of great importance in both academic research and industry. In the past several years, significant progresses have been made in the field of direct C-S bond construction for the synthesis of organosulfur compounds. Various synthetic methods have been developed to provide easy accesses to sulfides, sulfoxides, and sulfones from the non-halide substrates. Unlike C-S coupling reaction of halide substrates, a radical pathway was often involved in the C-S coupling reaction of non-halide substrates. It is satisfying that many reactions are featured by mild conditions, high efficiency and excellent selectivity by the employment of radical-radical coupling strategies. The Diazo compound is frequently used as carbon radical precursor to couple with the thiyl radical; however, this transformation may be limited by pre-functionalization of the substrate and poor atom-economy. C-H functionalization represents a promising strategy to produce carbon radicals from simple arenes and alkanes. A variety of $\mathrm{C}\left(s p^{3}\right)-\mathrm{H}$ and $\mathrm{C}\left(s p^{2}\right)-\mathrm{H}$ bonds are successfully transformed to the corresponding sulfides, sulfoxides, and sulfones. On the other hand, in addition to reactions catalyzed by traditional transition metals, novel protocols involving photocatalysts have been extensively developed in very recent years. Electrolysis mediated reactions also found application in the C-S coupling reaction for the synthesis of sulfides and sulfones from (hetero)arenes. These novel protocols enable the C-S coupling reaction to occur in a simple, economical, and efficient reaction system. In the future, C-S bond formation should get more benefits from photo-catalyzed and electrochemical reaction, and more novel protocols in this field can be expected.

Author Contributions: R.Z. wrote original draft; H.D. revised the manuscript and corrected the schemes; X.P. searched literatures and drew the original figures and schemes; Z.Q. searched literatures; Y.X. was responsible for conceptualization, supervision and editing. All authors have read and agreed to the published version of the manuscript.

Funding: This work was funded by the Natural Science Foundation of Liaoning Province, Grant No. 2019-ZD-0453.

Conflicts of Interest: The authors declare no conflict of interest.

\section{References}

1. Cremlyn, R.J. An Introduction to Organosulfur Chemistry; John Wiley and Sons: Chichester, UK, 1996.

2. Mampuys, P.; McElroy, C.R.; Clark, J.H.; Orru, R.V.A.; Maes, B.U.W. Thiosulfonates as emerging reactants: Synthesis and applications. Adv. Synth. Catal. 2020, 362, 3-64. [CrossRef]

3. Parcell, S. Sulfur in human nutrition and applications in medicine. Altern. Med. Rev. 2002, 7, 22-44. [PubMed]

4. Feng, M.; Tang, B.; Liang, S.H.; Jiang, X. Sulfur containing scaffolds in drugs: Synthesis and application in medicinal chemistry. Curr. Top. Med. Chem. 2016, 16, 1200-1216. [CrossRef]

5. Devendar, P.; Yang, G.-F. Sulfur-containing agrochemicals. Top. Curr. Chem. 2017, 375, 82. [CrossRef]

6. Li, X.; Ma, W.; Li, H.; Zhang, Q.; Liu, H. Sulfur-functionalized metal-organic frameworks: Synthesis and applications as advanced adsorbents. Coord. Chem. Rev. 2020, 408, 213191. [CrossRef]

7. Ferro, C.T.B.; Dos Santos, B.F.; da Silva, C.D.G. Review of the syntheses and activities of some sulfur-containing drugs. Curr. Org. Synth. 2020, 17, 192-210. [CrossRef]

8. Wang, N.; Saidhareddy, P.; Jiang, X. Construction of sulfur-containing moieties in the total synthesis of natural products. Nat. Prod. Rep. 2020, 37, 246-275. [CrossRef]

9. Ley, S.V.; Thomas, A.W. Modern synthetic methods for copper-mediated C(aryl)-O, C(aryl)-N, and C(aryl)-S bond formation. Angew. Chem. Int. Ed. 2003, 42, 5400-5449. [CrossRef] 
10. Liu, Y.; Liu, S.; Xiao, Y. Transition-metal-catalyzed synthesis of phenols and aryl thiols. Beilstein J. Org. Chem. 2017, 13, 589-611. [CrossRef]

11. Chen, L.; Fajer, A.N.; Yessimbekov, Z.; Kazemi, M.; Mohammadi, M. Diaryl sulfides synthesis: Copper catalysts in C-S bond formation. J. Sulfur Chem. 2019, 40, 451-468. [CrossRef]

12. Shen, C.; Zhang, P.; Sun, Q.; Bai, S.; Hor, T.S.A.; Liu, X. Recent advances in C-S bond formation via C-H bond functionalization and decarboxylation. Chem. Soc. Rev. 2015, 44, 291-314. [CrossRef] [PubMed]

13. Lee, C.-F.; Basha, R.S.; Badsara, S.S. Engineered C-S bond construction. Top. Curr. Chem. 2018, 376, 25. [CrossRef] [PubMed]

14. Arisawa, M.; Yamaguchi, M. Rhodium-catalyzed synthesis of organosulfur compounds involving S-S bond cleavage of disulfides and sulfur. Molecules 2020, 25, 3595. [CrossRef] [PubMed]

15. Ford, A.; Miel, H.; Ring, A.; Slattery, C.N.; Maguire, A.R.; McKervey, M.A. Modern organic synthesis with $\alpha$-diazocarbonyl compounds. Chem. Rev. 2015, 115, 9981-10080. [CrossRef]

16. Ciszewski, Ł.W.; Rybicka-Jasińska, K.; Gryko, D. Recent developments in photochemical reactions of diazo compounds. Org. Biomol. Chem. 2019, 17, 432-448. [CrossRef]

17. Khanal, H.D.; Kim, S.H.; Lee, Y.R. Rhodium(ii)-catalyzed direct sulfenylation of diazooxindoles with disulfides. RSC Adv. 2016, 6, 58501-58510. [CrossRef]

18. Zhang, Z.; Kong, P.; Wang, X.-C. An approach for synthesis of dithioacetals by CuI-catalyzed C-S coupling reaction of N-tosylhydrazone with disulfides. ChemistrySelect 2018, 3, 5667-5669. [CrossRef]

19. Song, F.; Gou, T.; Wang, B.-Q.; Shi, Z.-J. Catalytic activations of unstrained C-C bond involving organometallic intermediates. Chem. Soc. Rev. 2018, 47, 7078-7115. [CrossRef]

20. $\mathrm{Wu}, \mathrm{X}$; Z Zhu, C. Recent advances in radical-mediated C-C bond fragmentation of non-strained molecules. Chin. J. Chem. 2019, 37, 171-182. [CrossRef]

21. Wu, X.; Wang, Y. Metal-free S-methylation of diaryl disulfides with di-tert-butyl peroxide. Tetrahedron Lett. 2018, 59, 1240-1243. [CrossRef]

22. Smaligo, A.J.; Kwon, O. Dealkenylative thiylation of $\mathrm{C}\left(\mathrm{sp}^{3}\right)-\mathrm{C}\left(\mathrm{sp}^{2}\right)$ Bonds. Org. Lett. 2019, 21, 8592-8597. [CrossRef] [PubMed]

23. Shahidzadeh, E.S.; Nowrouzi, N.; Abbasi, M. Utilizing 2-phenylpropanal as coupling partner for C-S bond formation via sequential thioarylation and decarbonylation process: A novel strategy for the synthesis of aryl alkyl sulfides. Appl. Organomet. Chem. 2019, 33, e5211. [CrossRef]

24. Qin, Y.; Han, Y.; Tang, Y.; Wei, J.; Yang, M. A general method for site-selective Csp ${ }^{3}$-S bond formation via cooperative catalysis. Chem. Sci. 2020, 11, 1276-1282. [CrossRef]

25. Zhao, J.; Yang, F.; Yu, Z.; Tang, X.; Wu, Y.; Ma, C.; Meng, Q. Copper(I)-catalyzed sulfenylation of 1,3-dicarbonyl substrates with disulfides under mild conditions. Synlett 2019, 30, 2181-2184.

26. An, R.; Liao, L.; Liu, X.; Song, S.; Zhao, X. Acid-catalyzed oxidative cleavage of S-S and Se-Se bonds with DEAD: Efficient access to sulfides and selenides. Org. Chem. Front. 2018, 5, 3557-3561. [CrossRef]

27. Liu, Z.; Quyang, K.; Yang, N. The thiolation of pentafluorobenzene with disulfides by C-H, C-F bond activation and C-S bond formation. Org. Biomol. Chem. 2018, 16, 988-992. [CrossRef]

28. Noikham, M.; Yotphan, S. Copper-catalyzed regioselective direct $\mathrm{C}-\mathrm{H}$ thiolation and thiocyanation of uracils. Eur. J. Org. Chem. 2019, 2019, 2759-2766. [CrossRef]

29. Zheng, C.; Lu, F.; Lu, H.; Xin, J.; Deng, Y.; Yang, D.; Wang, S.; Huang, Z.; Gao, M.; Lei, A. Copper-catalyzed selective radical-radical cross-coupling for C-S bond formation: An access to $\alpha$-alkylthionitriles. Chem. Commun. 2018, 54, 5574-5577. [CrossRef]

30. Chand, S.; Pandey, A.K.; Singh, R.; Kumar, S.; Singh, K.N. Eosin-Y-catalyzed photoredox C-S bond formation: Easy access to thioethers. Chem. Asian J. 2019, 14, 4712-4716. [CrossRef]

31. Yi, X.; Feng, J.; Huang, F.; Baell, J.B. Metal-free C-C, C-O, C-S and C-N bond formation enabled by SBA-15 supported TFMSA. Chem. Commun. 2020, 56, 1243-1246. [CrossRef]

32. Jiang, W.; Li, N.; Zhou, L.; Zeng, Q. Copper-catalyzed stereospecific C-S coupling reaction of enantioenriched tertiary benzylic amines via in situ activation with methyl triflate. ACS Catal. 2018, 8, 9899-9906. [CrossRef]

33. Kolb, M. Ketene dithioacetals in organic synthesis: Recent developments. Synthesis 1990, 1990, 171-190. [CrossRef]

34. Zou, J.; Wang, Y.; Huang, L.; Jiang, Y.; Chen, J.; Zhu, L.; Yang, Y.; Feng, Y.; Peng, X.; Wang, Z. One pot preparation of $\alpha$-dithioacetal/ $\alpha$-diselenoacetal amides via a dual-C-S/C-Se bond formation and $\mathrm{C}-\mathrm{C}$ bond cleavage cascade of 3-oxo-butanamides. Org. Chem. Front. 2018, 5, 2317-2321. [CrossRef] 
35. Basha, R.S.; Chen, C.-W.; Reddy, D.M.; Lee, C.-F. Iodine-mediated direct generation of $o$-quinone methides at room temperature: A facile protocol for the synthesis of ortho-hydroxybenzyl thioethers. Chem. Asian J. 2018, 13, 2475-2483. [CrossRef]

36. Roy, D.; Panda, G. A dehydrative arylation and thiolation of tertiary alcohols catalyzed by in situ generated triflic acid-Viable protocol for C-C and C-S bond formation. Tetrahedron 2018, 74, 6270-6277. [CrossRef]

37. Hu, B.; Zhang, Q.; Zhao, S.; Wang, Y.; Xu, L.; Yan, S.; Yu, F. Direct oxidative disulfenylation/cyclization of 2 '-hydroxyacetophenones with thiophenols for the synthesis of 2,2-dithio-benzofuran-3(2H)-ones. Adv. Synth. Catal. 2019, 361, 49-54. [CrossRef]

38. Li, C.; Li, J.; Tan, C.; Wu, W.; Jiang, H. DDQ-mediated regioselective C-S bond formation: Efficient access to allylic sulfides. Org. Chem. Front. 2018, 5, 3158-3162. [CrossRef]

39. Huang, L.-S.; Han, D.-Y.; Xu, D.-Z. Iron-catalyzed cross-dehydrogenative coupling of oxindoles with thiols/selenols for direct $\mathrm{C}\left(\mathrm{sp}^{3}\right)-\mathrm{S} / \mathrm{Se}$ bond formation. Adv. Synth. Catal. 2019, 361, 4016-4021. [CrossRef]

40. Benoit, E.; Bueno, B.; Choiniere, C.; Gagnon, A. First use of an organobismuth reagent in $\mathrm{C}\left(\mathrm{sp}^{3}\right)-\mathrm{S}$ bond formation: Access to aryl cyclopropyl sulfides via copper-catalyzed S-cyclopropylation of thiophenols using tricyclopropylbismuth. J. Organomet. Chem. 2019, 893, 72-77. [CrossRef]

41. Tian, J.; Yuan, S.; Xiao, F.; Huang, H.; Deng, G.-J. Concise synthesis of N-thiomethyl benzoimidazoles through base-promoted sequential multicomponent assembly. RSC Adv. 2019, 9, 30570-30574. [CrossRef]

42. Zou, J.-X.; Jiang, Y.; Lei, S.; Yin, G.-F.; Hu, X.-L.; Zhao, Q.-Y.; Wang, Z. Synthesis of $\alpha$-arylthioacetones using TEMPO as the $C 3$ synthon via a reaction cascade of sequential oxidation, skeletal rearrangement and C-S bond formation. Org. Biomol. Chem. 2019, 17, 2341-2345. [CrossRef] [PubMed]

43. Hosseinian, A.; Nezhad, P.D.K.; Ahmadi, S.; Rahmani, Z.; Monfared, A. A walk around the decarboxylative C-S cross-coupling reactions. J. Sulfur Chem. 2019, 40, 88-112. [CrossRef]

44. Li, M.; Hoover, J.M. Aerobic copper-catalyzed decarboxylative thiolation. Chem. Commun. 2016, 52, 8733-8736. [CrossRef] [PubMed]

45. Jafarpour, F.; Asadpour, M.; Azizzade, M.; Ghasemi, M.; Rajai-Daryasarei, S. An iodide-mediated transition-metal-free strategy towards unsymmetrical diaryl sulfides via arylhydrazines and thiols. Synthesis 2020, 52, 727-734. [CrossRef]

46. Moghaddam, F.M.; Pourkaveh, R.; Gholamtajari, M. Nano CoCuFe ${ }_{2} \mathrm{O}_{4}$-catalyzed coupling reaction of arylboronic acid with amines and thiols: An atom-economic and ligand-free route to access unsymmetrical amines and sulfides. Appl. Organomet. Chem. 2018, 32, e4568. [CrossRef]

47. Singh, D.; Kumar, G.; Dheer, D.; Jyoti; Kushwaha, M.; Ahmed, Q.N.; Shankar, R. BCl 3 -mediated C-N, C-S, and C-O bond formation of imidazo[1,2-a]pyridine benzylic ethers. ACS Omega 2019, 4, 4530-4539. [CrossRef]

48. Ghosh, P.; Nandi, A.K.; Chhetri, G.; Das, S. Generation of ArS- and ArSe-substituted 4-quinolone derivatives using sodium iodide as an inducer. J. Org. Chem. 2018, 83, 12411-12419. [CrossRef]

49. Choudhuri, K.; Maiti, S.; Mal, P. Iodine(III) enabled dehydrogenative aryl C-S coupling by in situ generated sulfenium ion. Adv. Synth. Catal. 2019, 361, 1092-1101. [CrossRef]

50. Huang, X.; Chen, Y.; Zhen, S.; Song, L.; Gao, M.; Zhang, P.; Li, H.; Yuan, B.; Yang, G. Cobalt-catalyzed aerobic cross-dehydrogenative coupling of C-H and thiols in water for C-S formation. J. Org. Chem. 2018, 83, 7331-7340. [CrossRef]

51. Yuan, Y.; Cao, Y.; Qiao, J.; Lin, Y.; Jiang, X.; Weng, Y.; Tang, S.; Lei, A. Electrochemical oxidative C-H sulfenylation of imidazopyridines with hydrogen evolution. Chin. J. Chem. 2019, 37, 49-52. [CrossRef]

52. Liu, S.; Deng, G.-J.; Huang, H. Recent advances in sulfur-containing heterocycle formation via direct C-H sulfuration with elemental sulfur. Synlett 2020, 31. [CrossRef]

53. Semwal, R.; Ravi, C.; Saxena, S.; Adimurthy, S. Copper-catalyzed multicomponent reactions (MCRs) for disulfenylation of imidazo[1,2-a]pyridines using elemental sulfur and arylhalides and intramolecular cyclization of haloimidazo[1,2-a]pyridines. J. Org. Chem. 2019, 84, 14151-14160. [CrossRef] [PubMed]

54. Atashkar, B.; Rostami, A.; Rostami, A.; Zolfigol, M.A. $\mathrm{NiFe}_{2} \mathrm{O}_{4}$ as a magnetically recoverable nanocatalyst for odourless $\mathrm{C}-\mathrm{S}$ bond formation via the cleavage of $\mathrm{C}-\mathrm{O}$ bond in the presence of $\mathrm{S} 8$ under mild and green conditions. Appl. Organomet. Chem. 2019, 33, e4691. [CrossRef]

55. Khakyzadeh, V.; Rostami, A.; Veisi, H.; Shaghasemi, B.S.; Reimhult, E.; Luque, R.; Xia, Y.; Darvishi, S. Direct $\mathrm{C}-\mathrm{S}$ bond formation via $\mathrm{C}-\mathrm{O}$ bond activation of phenols in a crossover $\mathrm{Pd} / \mathrm{Cu}$ dual-metal catalysis system. Org. Biomol. Chem. 2019, 17, 4491-4497. [CrossRef] 
56. Ghosh, A.; Lecomte, M.; Kim-Lee, S.-H.; Radosevich, A.T. Organophosphorus-catalyzed deoxygenation of sulfonyl chlorides: Electrophilic (fluoroalkyl)sulfenylation by $\mathrm{P}^{\mathrm{III}} / \mathrm{P}^{\mathrm{V}}=\mathrm{O}$ redox cycling. Angew. Chem. Int. Ed. 2019, 58, 2864-2869. [CrossRef]

57. Huang, K.; Yang, M.; Lai, X.-J.; Hu, X.; Qiu, G.; Liu, J.-B. CuI-catalyzed direct synthesis of diaryl thioethers from arylboronic acids and arylsulfonyl chlorides. Appl. Organometal. Chem. 2019, 33, e5385.

58. Zhao, F.; Tan, Q.; Wang, D.; Chen, J.; Deng, G.-J. Efficient C-S bond formation by direct functionalization of $\mathrm{C}\left(\mathrm{sp}^{3}\right)-\mathrm{H}$ bond adjacent to heteroatoms under metal-free conditions. Adv. Synth. Catal. 2019, 361, 4075-4081. [CrossRef]

59. Guo, W.-S.; Gong, H.; Zhang, Y.-A.; Wen, L.-R.; Li, M. Fast construction of 1,3-benzothiazepines by direct intramolecular dehydrogenative C-S bond formation of thioamides under metal-free conditions. Org. Lett. 2018, 20, 6394-6397. [CrossRef]

60. Ishitobi, K.; Muto, K.; Yamaguchi, J. Pd-catalyzed alkenyl thioether synthesis from thioesters and N-tosylhydrazones. ACS Catal. 2019, 9, 11685-11690. [CrossRef]

61. Pandey, A.K.; Chand, S.; Singh, R.; Kumar, S.; Singh, K.N. Iodine-catalyzed synthesis of 3-arylthioindoles employing a 1-aryltriazene/CS ${ }_{2}$ combination as a new sulfenylation source. ACS Omega 2020, 5, 7627-7635. [CrossRef]

62. Huang, Y.; Zhang, M.; Lin, Q.; Weng, Z. [(bpy) $\left.\mathrm{CuSCF}_{3}\right]$ : A Practical and Efficient Reagent for the Construction of C-SCF3 Bonds. Synlett 2020, 31. [CrossRef]

63. Honeker, R.; Garza-Sanchez, R.A.; Hopkinson, M.N.; Glorius, F. Visible-light-promoted trifluoromethylthiolation of styrenes by dual photoredox/halide catalysis. Chem. Eur. J. 2016, 22, 4395-4399. [CrossRef] [PubMed]

64. Li,H.; Shan, C.C.; Tung, C.-H.; Xu, Z. Dual gold and photoredox catalysis: Visible light-mediated intermolecular atom transfer thiosulfonylation of alkenes. Chem. Sci. 2017, 8, 2610-2615. [CrossRef] [PubMed]

65. Dagousset, G.; Simon, C.; Anselmi, E.; Tuccio, B.; Billard, T.; Magnier, E. Generation of the SCF 3 radical by photoredox catalysis: Intra- and intermolecular carbotrifluoromethylthiolation of alkenes. Chem. Eur. J. 2017, 23, 4282-4286. [CrossRef] [PubMed]

66. Zhao, X.; Yang, B.; Wei, A.; Sheng, J.; Tian, M.; Li, Q.; Lu, K. Silver-mediated radical aryltrifluoromethylthiolation of activated alkenes by S-trifluoromethyl 4-methylbenzenesulfonothioate. Tetrahedron Lett. 2018, 59, 1719-1722. [CrossRef]

67. Yu, H.; Li, Z.; Bolm, C. Transition-metal-free arylations of in-situ generated sulfenates with diaryliodonium salts. Org. Lett. 2018, 20, 7104-7106. [CrossRef]

68. Shi, W.; Miao, T.; Li, Y.; Li, P.; Wang, L. Selective synthesis of diaryl sulfoxides and m-arylthio sulfones from arylsulfinic acids and arenes via BF 3 -promoted C-S bond formation. Org. Lett. 2018, 20, 4416-4420. [CrossRef]

69. Zhao, J.-L.; Guo, S.-H.; Qiu, J.; Gou, X.-F.; Hua, C.-W.; Chen, B. Iron(III) phthalocyanine-chloride-catalyzed synthesis of sulfones from sulfonylhydrazones. Tetrahedron Lett. 2016, 57, 2375-2378. [CrossRef]

70. Deng, L.; Kleij, A.W.; Yang, W. Diversity-orientated stereoselective synthesis through Pd-catalyzed switchable decarboxylative C-N/C-S bond formation in allylic surrogates. Chem. Eur. J. 2018, 24, 19156-19161. [CrossRef]

71. Wang, F.; Xu, P.; Wang, S.-Y.; Ji, S.-J. Cu(II)/Ag(I)-catalyzed cascade reaction of sulfonylhydrazone with anthranils: Synthesis of 2-aryl-3-sulfonyl substituted quinoline derivatives. Org. Lett. 2018, 20, 2204-2207. [CrossRef]

72. Zhu, X.-Y.; Han, Y.-P.; Li, M.; Li, X.-S.; Liang, Y.-M. Copper-catalyzed radical sulfonylation of N-propargylindoles with concomitant 1,2-aryl migration. Adv. Synth. Catal. 2018, 360, 3460-3465. [CrossRef]

73. Liu, T.; Liu, J.; Xia, S.; Meng, J.; Shen, X.; Zhu, X.; Chen, W.; Sun, C.; Cheng, F. Catalyst-free 1,6-conjugate addition/aromatization/sulfonylation of para-quinone methides: Facile access to diarylmethyl sulfones. ACS Omega 2018, 3, 1409-1415. [CrossRef] [PubMed]

74. Meng, F.-X.; Wang, R.-N.; Huang, H.-L.; Gong, S.-W.; Li, Q.-L.; Zhang, S.-L.; Ma, C.-L.; Li, C.-Z.; Du, J.-Y. Lewis acid-catalyzed tandem cyclization of in situ generated $o$-quinone methides and arylsulfonyl hydrazides for a one-pot entry to 3-sulfonylbenzofurans. Org. Chem. Front. 2019, 6, 3929-3933. [CrossRef]

75. Pagire, S.K.; Hossain, A.; Reiser, O. Temperature controlled selective C-S or C-C bond formation: Photocatalytic sulfonylation versus arylation of unactivated heterocycles utilizing aryl sulfonyl chlorides. Org. Lett. 2018, 20, 648-651. [CrossRef]

76. Kuchukulla, R.R.; Li, F.; He, Z.; Zhou, L.; Zeng, Q. Synthesis of sultams and cyclic N-sulfonyl ketimines via iron-catalyzed intramolecular aliphatic C-H amidation. Green Chem. 2019, 21, 5808-5812. [CrossRef] 
77. Johnson, T.C.; Elbert, B.L.; Farley, A.J.M.; Gorman, T.W.; Genicot, C.; Lallemand, B.; Pasau, P.; Flasz, J.; Castro, J.L.; MacCoss, M.; et al. Direct sulfonylation of anilines mediated by visible light. Chem. Sci. 2018, 9, 629-633. [CrossRef]

78. Nikl, J.; Ravelli, D.; Schollmeyer, D.; Waldvogel, S.R. Straightforward electrochemical sulfonylation of arenes and aniline derivatives using sodium sulfinates. ChemElectroChem 2019, 6, 4450-4455. [CrossRef]

79. Rao, C.; Mai, S.; Song, Q. Rh(ii)/phosphine-cocatalyzed synthesis of dithioketal derivatives from diazo compounds through simultaneous construction of two different C-S bonds. Chem. Commun. 2018, 54, 5964-5967. [CrossRef]

80. Reddy, R.J.; Waheed, M.; Krishna, G.R. Phenylboronic acid-catalyzed tandem construction of S-S and C-S bonds: A new method for the synthesis of benzyl disulfanylsulfone derivatives from S-benzyl thiosulfonates. Org. Biomol. Chem. 2020, 18, 3243-3248. [CrossRef]

Publisher's Note: MDPI stays neutral with regard to jurisdictional claims in published maps and institutional affiliations.

(C) 2020 by the authors. Licensee MDPI, Basel, Switzerland. This article is an open access article distributed under the terms and conditions of the Creative Commons Attribution (CC BY) license (http://creativecommons.org/licenses/by/4.0/). 